\title{
The role of glacial isostatic adjustment in the present-day crustal motion and sea levels of East Asia
}

\author{
Hansheng Wang ${ }^{1}$, Patrick $\mathrm{Wu}^{2}$, Lulu Jia ${ }^{1,3}, \mathrm{Bo} \mathrm{Hu}^{1,3}$, and Liming Jiang ${ }^{1}$ \\ ${ }^{1}$ Key Laboratory of Dynamical Geodesy, Institute of Geodesy and Geophysics, Chinese Academy of Sciences, Wuhan 430077, China \\ ${ }^{2}$ Department of Geoscience, University of Calgary, Calgary T2N 1N4, Canada \\ ${ }^{3}$ Graduate University of Chinese Academy of Sciences, Beijing 100049, China
}

(Received December 15, 2010; Revised April 14, 2011; Accepted May 11, 2011; Online published December 29, 2011)

\begin{abstract}
The aim of this paper is to model and remove the contribution of glacial isostatic adjustment (GIA) from the observed crustal velocities and sea-level rates in East Asia, so that the signal from other geological processes such as tectonic uplift or global change can be better revealed. State-of-the-art GIA models that include 3D variations in mantle viscosity and lithospheric thickness are employed in this study. Uncertainties of the GIA response are estimated from different ice history and background viscosity models. It is demonstrated that the uncertainties in the GIA response in East Asia are generally small compared with the response itself. For example, the land uplift rate near the east coast of China due to GIA has magnitudes of about $0.1 \mathrm{~mm} / \mathrm{yr}$ while the uncertainties are generally less than $0.04 \mathrm{~mm} / \mathrm{yr}$. These are small compared with the observed magnitude of uplift rate $(\sim 1.0 \mathrm{~mm} / \mathrm{yr})$ and the measurement uncertainties of GPS. For the height rates in leveling observation, relative sea-level rates in tide gauge data, absolute seal-level rates from satellite altimetry and tangential velocities from GPS data, the GIA effects are also shown to be generally small compared with observed data. This technique of "cleaning" geodetic data will become more useful in the future when the uncertainties of geodetic measurements can be reduced to less than $0.1 \mathrm{~mm} / \mathrm{yr}$.
\end{abstract}

Key words: Glacial isostatic adjustment, lateral heterogeneity, crustal motion, sea levels, East Asia.

\section{Introduction}

The ongoing response of the viscoelastic Earth to changes in surface ice and water loads during and after the last Ice Age is called Glacial Isostatic Adjustment (GIA). The effect of GIA is global as it modi es the Earth's shape, its gravitational eld and the motion of its rotational pole. Traditionally, modeling the GIA process has led to a better understanding of the Earth's rheology and ice thickness history. However, the effect of GIA has been modeled and removed from global sea-level and tide-gauge observations to monitor global warming (Peltier, 1986; Davis and Mitrovica, 1996; Han and Huang, 2009; Trisirisatayawong et al., 2011). Recently, Klemann et al. (2008) showed that the magnitude of the GIA signal is of the order of accuracy of plate motion. In the same spirit, geodetic measurements in East Asia are contaminated by GIA signals, thus this paper investigates the effects of GIA on present-day crustal motion and sea levels in East Asia to see if GIA signals need to be removed before GPS and sea-level data can be interpreted for other geological processes.

East Asia is in the far eld of deglaciated areas of North America, Northern Europe, Antarctic and Greenland, thus, except for horizontal crustal velocity, the effect of GIA is likely to be too small to be measurable by today's tech-

Copyright (C) The Society of Geomagnetism and Earth, Planetary and Space Sciences (SGEPSS); The Seismological Society of Japan; The Volcanological Society of Japan; The Geodetic Society of Japan; The Japanese Society for Planetary Sciences; TERRAPUB.

doi:10.5047/eps.2011.05.002 nology. However, it may still be of interest to determine the GIA effect in East Asia due to far- eld deglaciation, since removing the contribution of GIA from the observations could help to reveal more clearly the signal from other geological processes. Moreover, the accuracy of geodetic measurements has been constantly improving so that in the not too distant future, these "small" GIA contributions may become detectable - a clear knowledge of the GIA signal level in these places will help instrument designers target the signal level and accuracies required.

Early models of the GIA process were based on laterallyhomogeneous Earth models (e.g., Mitrovica and Forte, 1997; Peltier, 1998; Kaufmann and Lambeck, 2000). However, surface geology and seismic tomography tell us that the Earth is laterally heterogeneous. Furthermore, the effects of lateral heterogeneities have been shown to be signi cant (Sabadini et al., 1986; Gasperini and Sabadini, 1989; Giunchi et al., 1997; Kaufmann et al., 1997, 2000; Kaufmann and Wu, 1998, 2002). These earlier works were based on at-Earth models where a simplistic lateral variation in lithospheric thickness and/or asthenospheric viscosity were taken into account. More recently, seismic tomography models have been used to infer more realistic lateral viscosity changes in the mantle of a spherically-strati ed Earth (e.g., Kaufmann et al., 2005; Latychev et al., 2005a, b; Paulson et al., 2005; Wu, 2005; Wang and Wu, 2006a, b).

Recently, Wang et al. (2008, 2009) have developed a new GIA model where viscosity is allowed to vary both in 

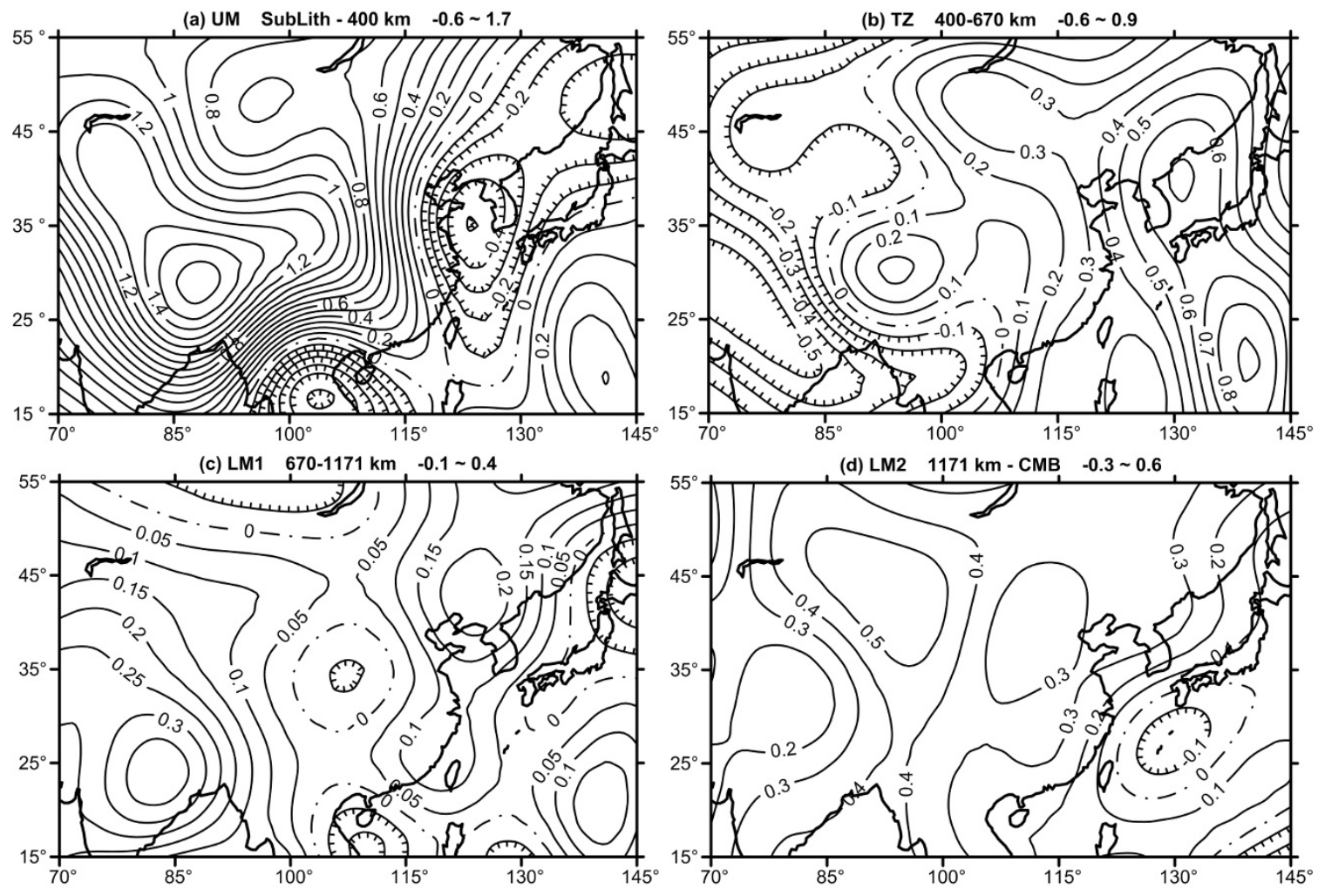

Fig. 1. Lateral perturbation in $\log 10$ of the mantle viscosity (in Pa s) in East Asia for the four mantle layers of the laterally-heterogeneous Earth model RF3L20 $(\beta=0.4)$. The name of the layer, the depth range, and numeric range are shown above each map.

the radial and lateral directions. The radial viscosity prole is given by model RF3 which is a simpli ed version of Peltier's VM2 model (Peltier, 1998). The lateral viscosity variation of this model, $\operatorname{RF} 3 \mathrm{~L} 20(\beta=0.4)+\mathrm{ICE}-4 \mathrm{G}$, is inferred from shear-wave velocity anomalies of the seismic tomographic model S20A (Ekstrom and Dziewonski, 1998) using the scaling relationship of Ivins and Sammis (1995) multiplied by the factor $\beta$. The latter represents the fractional contribution of temperature variations to lateral variation in shear-wave velocity, and is constrained to be 0.4 by historic relative sea-level data (Tushingham and Peltier, 1991), GPS observations in Laurentide (Sella et al., 2007) and Fennoscandia (Lidberg et al., 2007), altimetry and tide-gauge data in the Great Lakes area (Kuo et al., 2008) and GRACE data in Laurentide (van der Wal et al., 2008). The ice load is given by Peltier's (1994) ICE-4G model. The Coupled Laplace-Finite Element method (Wu, 2004) is used to predict the GIA response on a spherical, self-gravitating, viscoelastic Earth with material compressibility in the solid Earth and self-gravitating oceans. Water in $\mathrm{ux}$ in previously glaciated areas (Hudson Bay) is also included in the model.

To summarize, this paper uses model RF3L20 $(\beta=0.4)+\mathrm{ICE}-4 \mathrm{G}$ to show how GIA affects the present-day crustal motion and sea levels in East Asia. The aims are: (1) to predict present-day GIA-induced uplift rates, height rates, tangential rates and sea-level rates and to assess the uncertainties due to the differences in reference viscosity models and deglacial models; (2) to study the effect of lateral heterogeneities in mantle viscosity and lithospheric thickness on the GIA predictions.

\section{Models}

As mentioned in Introduction, the model used is the laterally-heterogeneous Earth model $\operatorname{RF} 3 \mathrm{~L} 20(\beta=0.4)$ with deglacial model ICE-4G. In addition, laterallyhomogeneous Earth models RF2 and RF3, and deglacial model ICE-5G are also used to evaluate the uncertainties of GIA predictions.

\subsection{Earth models}

The density strati cation and elastic structure of all the Earth models used are the same and are given in table 1 of Wang et al. (2008). These Earth models contain ve layers between core-mantle-boundary (CMB) and the Earth's surface. From top to bottom, they are: the lithosphere (LITH), upper mantle (UM, sub-lithosphere-400 km depth), transition zone (TZ, 400-670 km depth), the shallow part of the lower mantle (LM1, 670-1171 km depth), and the deep part of the lower mantle (LM2, $1171 \mathrm{~km}$ depth-CMB).

The radial pro le of the background model RF3 (in the absence of lateral heterogeneity) is a simpli ed version of Peltier's (1998) VM2 model where the viscosities for layers UM, TZ, LM1 and LM2 are $0.6 \times 10^{21}, 3.0 \times 10^{21}$, $6.0 \times 10^{21}$ and $6.0 \times 10^{21} \mathrm{~Pa}$ s respectively. Superposed on this background viscosity pro le are the lateral viscosity perturbations inferred from velocity model S20A (Ekstrom and Dziewonski, 1998) with the scaling relationship given by Ivins and Sammis, (1995) and modi ed by $\beta=0.4$ (Wang et al., 2008, 2009). The lateral viscosity perturbations in the four mantle layers of model $\operatorname{RF} 3 \operatorname{L} 20(\beta=0.4)$ in East Asia is shown in Fig. 1 (see also gure 1 of Wang et al., 2009), from which it is seen that mantle viscosity varies more than 2 orders of magnitude in the upper mantle (UM), 


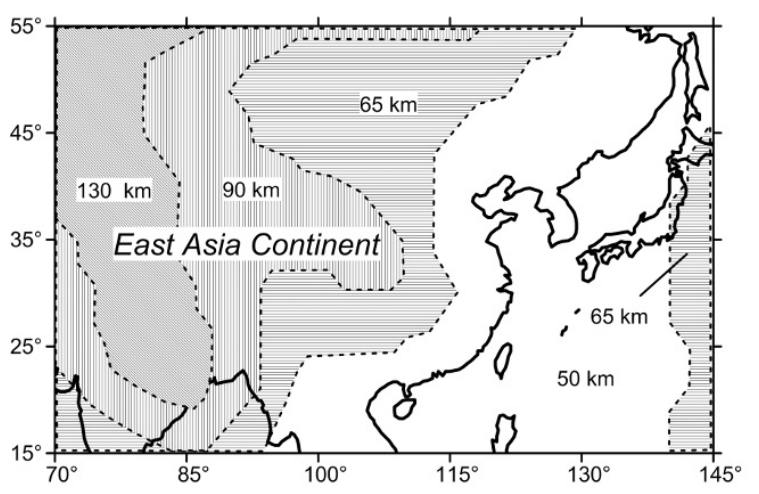

Fig. 2. Lateral variation in lithospheric thickness in East Asia for the laterally-heterogeneous Earth model RF3L20 $(\beta=0.4)$.

1.5 orders of magnitude in the transition zone (TZ), 0.5 orders of magnitude in the shallow part of the lower mantle (LM1), and nearly 1 order of magnitude in the deep part of the lower mantle (LM2). The lithosphere is assumed to be fully elastic with in nite viscosity, but lithospheric thickness is allowed to vary laterally (Fig. 2). The lithosphere is $50-\mathrm{km}$ thick under the East Asia Sea and along the continental coast; but towards the west, the lithospheric thickness increases to $65 \mathrm{~km}, 90 \mathrm{~km}$, and nally to $130 \mathrm{~km}$.

In order to study the effect of the background viscosity pro le, predictions from laterally homogeneous models RF3 and RF2 are also computed. RF2 is obtained from Mitrovica and Forte (1997)'s model where the viscosity in $\mathrm{UM}$ and $\mathrm{TZ}$ are $0.7 \times 10^{21} \mathrm{~Pa} \mathrm{~s}$, while those in LM1 and LM2 are $1.0 \times 10^{22} \mathrm{~Pa}$ s. Such high viscosity in the lower mantle has been shown by Mitrovica and Forte (1997) to have a strong effect on the far- eld horizontal motion. For models RF3 and RF2, the elastic lithosphere is $115-\mathrm{km}$ thick.

\subsection{Ice models}

As in Wang et al. (2008, 2009), the ice deglaciation history is taken to be Peltier's (1994) ICE-4G model. During the glacial phase from $108 \mathrm{ka}$ BP to $18 \mathrm{ka} \mathrm{BP}$ (the last glacial maximum or LGM), ice thickness is assumed to increase linearly at every ice location. However, during the deglaciation phase, the ice load disappearance is dependent on both location and time. According to the ICE-4G model, this time is around $10 \mathrm{kyr} \mathrm{BP}$ for Fennoscandia and to the south of Hudson Bay, and 6 kyr for Antarctica. The stepsize of the deglaciation phase is $1 \mathrm{kyr}$, and this starts from LGM to $6 \mathrm{kyr} \mathrm{BP}$, when Pleistocene deglaciation virtually stopped.

The ocean load is given by the sea-level changes which are obtained by solving the sea-level equation iteratively (see equation (21) of $\mathrm{Wu}(2004)$ ). Water in ux in previously glaciated areas (e.g. Hudson Bay) has been included. Rotational feedback is not implemented in the model.

In order to investigate the effects of different ice models, the ICE-5G model (Peltier, 2004) is also used, however the glaciation period is now from $108 \mathrm{kyr}$ BP to 26-22 kyr BP (LGM). Because East Asia is far away from the large ice sheets, we expect that differences between deglacial models ICE-4G and ICE-5G (Peltier, 2004) will have little effects on our results.
The existence of thick Pleistocene ice sheets over the Tibetan Plateau is controversial (Wang, 2001). Since there is not enough geological evidences to support the existence of such an ice sheet with continuous coverage over the Tibetan Plateau during the Pleistocene, Peltier left it out of both ICE-4G and ICE-5G models. In this paper, we take this stand and assume that there is no Pleistocene deglaciation in the Tibetan Plateau, and that current ice melting there is not included since the GIA responses just from Pleistocene ice-sheets are focused in this work.

\subsection{FEM model}

The Coupled-Laplace-Finite-Element (or CLFE) method of $\mathrm{Wu}$ (2004) is used to predict the GIA responses for the combinations of Earth models and ice models. The Earth is a spherical, self-gravitating, viscoelastic planet with selfgravitating oceans. In the Earth models above, material compressibility has been included in the lithosphere and the mantle. The lithosphere is assumed to be an elastic solid and the core is an inviscid uid.

The FE model consists of layers of 8-node-elements in the lithosphere and the mantle. The horizontal resolution at the surface is $2 \times 2^{\circ}$ for both ice and ocean loads. The spatial resolution of the model is limited by the computer resources available. Therefore, the vertical resolution of the Earth models is variable: with a larger grid size at deeper depth. This way the number of nodes in the FE model is reduced in order to save computation time. We have tested $1 \times 1^{\circ}$ and $1 \times 2^{\circ}$ grids and the differences in grid size do not signi cantly affect the results.

For the calculation of potential perturbations and sea levels (Wu, 2004), the spherical harmonic expansions are truncated at degree 90 for all cases. The CLFE computation is an iterative process: $4 \sim 5$ iterations are found to be necessary and suf cient for convergence.

\section{Lateral Heterogeneity and Uncertainties of GIA Predictions}

In this study, present-day uplift rates, tangential rates and geoid rates predicted by GIA model RF3L $20(\beta=0.4)+$ ICE$4 \mathrm{G}$ will be used. First, we shall show that the effects of lateral heterogeneity is important and cannot be neglected. Next, we consider the uncertainties of GIA predictions which are due to the uncertainties from a radial (background) viscosity pro le and the ice model. The uncertainty due to a radial viscosity pro le is estimated from the difference between the predictions of models RF2 and RF3, while the uncertainty due to the ice model is estimated from the difference in prediction between ICE-5G and ICE-4G. It should be noted that all the results in this paper concerning tangential rates (except Fig. 9(a)) are shown with the rotation components relative to the Eurasia Plate removed. Details can be found in Section 4.2.

\subsection{GIA predictions of model RF3L $20(\beta=0.4)+$ ICE- 4G}

The GIA predictions for model RF3L20 $(\beta=0.4)+$ ICE$4 \mathrm{G}$ is shown in Fig. 3. For uplift motion, Fig. 3(a) shows that the values are highest with magnitude greater than $0.2 \mathrm{~mm} / \mathrm{yr}$ in the eastern part of the continent and the largest uplift appears at Jian City $\left(26.6^{\circ} \mathrm{N}, 114.7^{\circ} \mathrm{E}\right)$, Jiangxi Province, China with a magnitude of $0.3 \mathrm{~mm} / \mathrm{yr}$. There is 

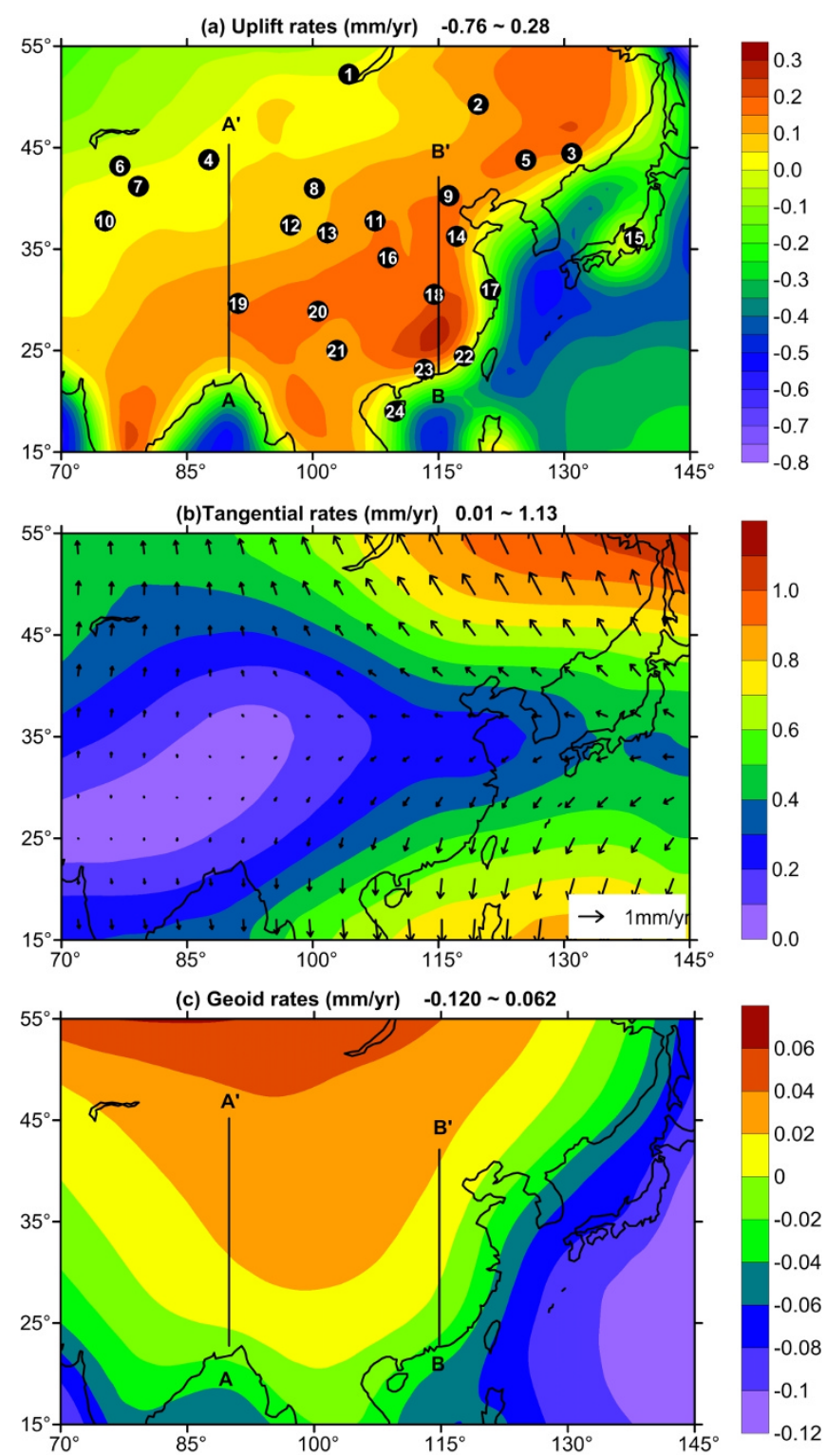

Fig. 3. Present-day GIA predictions in East Asia from model RF3L20( $\beta=0.4)+$ ICE-4G. (a) uplift rates; (b) tangential rates; (c) geoid rates. The units for the scale bars on the right are in mm/yr. Black circles with numbers denote the geodetic stations listed in Table 1 . $\mathrm{AA}^{\prime}$ and $\mathrm{BB}^{\prime}$ are the two leveling sections chosen for finding the effects of GIA contributions shown in Fig. 8.

subsidence in the East China Sea and the northern part of the South China Sea with magnitudes of $\sim 0.5-0.8 \mathrm{~mm} / \mathrm{yr}$. These vertical crustal motions on land are due to deglaciation in the far field (Fennoscandian ice-sheet, Siberian icesheet, North America ice-sheet complex, Antarctica, etc.). The motion near the coast has an added contribution from ocean loading by the melt water of these distant ice sheets which causes crustal tilting: uplift on land and extra subsidence just off the coast. The uplift rate is also affected by the deglaciation history, which controls its magnitude during the forcing period, and the viscosity structure of the Earth, which determines how fast the uplift rate changes with time after ice or water loading ends (Wu, 2005). If the viscosity is low, then GIA is most rapid near the end of loading and the present-day uplift rate might become small. On the other hand, too high a viscosity will suppress the flow motion in the mantle giving a small uplift at all times. Thus uplift rate is highest when the value of viscosity is interme- diate. In addition, the relative position of the lateral heterogeneity relative to the location of the ice forcing and the interaction between lateral heterogeneities of different depth layers are also important (Wu, 2005). The effect of lateral heterogeneity can be clearly seen below, when Fig. 3(a) is compared with Fig. 4(a).

Figure 3(b) shows that the magnitude of tangential motion is generally small but increases to the northeast and southeast. In the north, the direction is towards the north or northwest with peak magnitudes of $\sim 1.1 \mathrm{~mm} / \mathrm{yr}$; while in the south, the motion is towards the south and southwest with similar magnitude.

Figure 3(c) shows that the variation in geoid rate is much smoother than that in Fig. 3(a), with a magnitude ranging from $-0.12 \mathrm{~mm} / \mathrm{yr}$ to $0.06 \mathrm{~mm} / \mathrm{yr}$. The peak is located in the northern part of the East Asia continent while the trough occurs offshore to the east and to the south. 

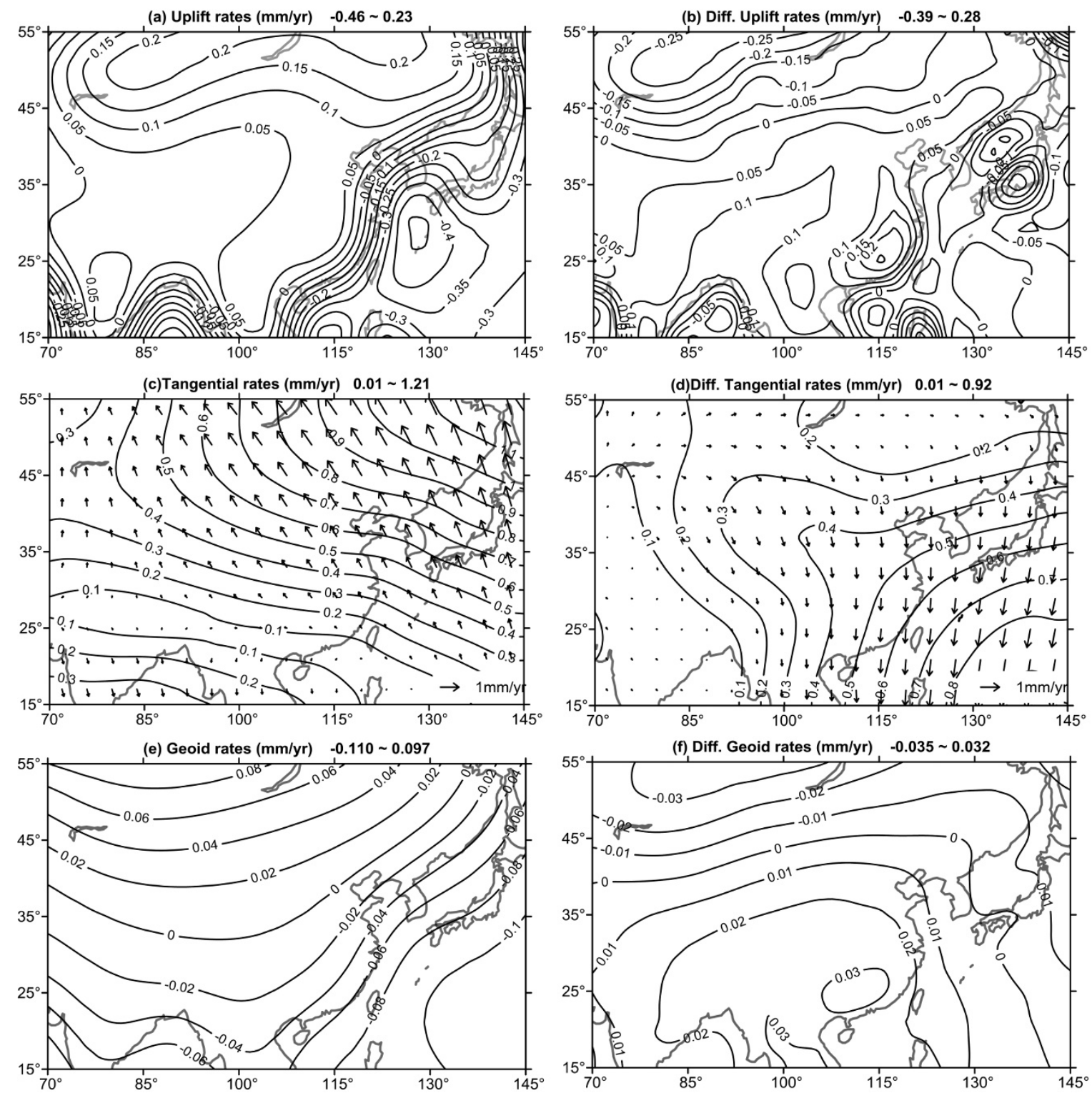

Fig. 4. Effects of lateral heterogeneity. Left panels show present-day uplift rates (a), tangential rates (c), and geoid rates (e) in East Asia predicted by GIA model RF3+ICE-4G. Right panels show their difference when compared with model RF3L20( $\beta=0.4)+$ ICE-4G (Fig. 3(a, b, c)). Units are in $\mathrm{mm} / \mathrm{yr}$.

\subsection{Effects of lateral heterogeneities}

Figure 4 shows the predictions from the laterallyhomogeneous model RF3, and its difference with the laterally-heterogeneous model $\operatorname{RF} 3 \operatorname{L} 20(\beta=0.4)$. Such a comparison reveals the effects of lateral heterogeneities in mantle viscosity and lithospheric thickness.

Due to the presence of lateral heterogeneities, the peak in uplift motion moves from the north in Fig. 4(a) to the south along the coast in Fig. 3(a). The peak magnitude is reduced by $\sim 0.2 \mathrm{~mm} / \mathrm{yr}$ in the north and increased by $\sim 0.3 \mathrm{~mm} / \mathrm{yr}$ in the south along the coast. However, it is not an easy task to pinpoint the exact cause of the uplift peaks and troughs in Figs. 3(a) or 4(b) because the amplitude of the response is controlled by many factors (see the discussion in the last subsection) and that the interacting effects of lateral variations in lithospheric thickness and mantle viscosity of all the layers have to be considered $(\mathrm{Wu}, 2005)$ in addition to the sensitivity kernel of the data $(\mathrm{Wu}, 2006)$. In particu- lar, the lateral viscosity variations in layer TZ is opposite to that in UM and LM, and so the net interaction of the different layers are quite complex and preclude any simple interpretation of why certain peaks and troughs are there in the maps of uplift rate, geoid rate or tangential velocity.

As in Kaufmann et al. (2005), the presence of lateral heterogeneities alters the pattern of tangential motion: Here, Fig. 4(c), shows that the tangential motion in the south becomes very small and the direction is reversed.

For geoidal rates, the presence of heterogeneities reduces the peak in the north (Fig. 4(e)) by $\sim 0.04 \mathrm{~mm} / \mathrm{yr}$ and thus give a smoother change in Fig. 3(c).

These results show that the effects of lateral heterogeneities are not insigni cant and should not be neglected for the GIA predictions of East Asia. Therefore, the laterally-heterogeneous model $\operatorname{RF} 3 \operatorname{L} 20(\beta=0.4)$ is used below (except Fig. 5). 
Table 1. Comparisons between the uplift rates at the geodetic stations of East Asia predicted from GIA model RF3L20( $\beta=0.4)+\mathrm{ICE}-4 \mathrm{G}$ and those from GPS measurements (Liu, 2004).

\begin{tabular}{|c|c|c|c|c|c|c|c|c|c|c|c|}
\hline $\begin{array}{c}\text { Station } \\
\text { No. }\end{array}$ & $\begin{array}{l}\text { Station } \\
\text { name }\end{array}$ & $\begin{array}{l}\text { Long. } \\
{ }^{\circ} \mathrm{E}\end{array}$ & $\begin{array}{c}\text { Latt. } \\
{ }^{\circ} \mathrm{N}\end{array}$ & $\begin{array}{c}U^{\text {GIA }} \\
\mathrm{mm} / \mathrm{yr}\end{array}$ & $\begin{array}{c}U_{3}^{\text {GIA }} \\
\mathrm{mm} / \mathrm{yr}\end{array}$ & $\begin{array}{c}U_{2}^{\text {GIA }} \\
\mathrm{mm} / \mathrm{yr}\end{array}$ & $\begin{array}{c}U_{5}^{\text {GIA }} \\
\mathrm{mm} / \mathrm{yr}\end{array}$ & $\begin{array}{c}\sigma_{U} \mathrm{GIA} \\
\mathrm{mm} / \mathrm{yr}\end{array}$ & $\begin{array}{c}U^{\mathrm{GPS}} \\
\mathrm{mm} / \mathrm{yr}\end{array}$ & $\begin{array}{l}\sigma_{U} \mathrm{GPS} \\
\mathrm{mm} / \mathrm{yr}\end{array}$ & $\begin{array}{c}U^{\prime} \\
\mathrm{mm} / \mathrm{yr}\end{array}$ \\
\hline 1 & Irkutsk & 104.32 & 52.22 & 0.02 & 0.18 & 0.00 & 0.27 & 0.16 & 0.53 & 0.10 & 0.51 \\
\hline 2 & Hailaer & 119.73 & 49.27 & 0.11 & 0.19 & 0.12 & 0.20 & 0.06 & 0.77 & 0.36 & 0.66 \\
\hline 3 & Suiyang & 130.90 & 44.43 & 0.16 & 0.08 & 0.11 & 0.20 & 0.03 & -1.96 & 0.30 & -2.12 \\
\hline 4 & Urumqi & 87.60 & 43.80 & 0.02 & 0.12 & 0.05 & 0.16 & 0.07 & 2.14 & 0.28 & 2.12 \\
\hline 5 & Changchun & 125.44 & 43.79 & 0.17 & 0.14 & 0.18 & 0.23 & 0.04 & 1.70 & 0.27 & 1.53 \\
\hline 6 & Selezaschita & 77.02 & 43.18 & -0.01 & 0.10 & 0.03 & 0.11 & 0.07 & -3.06 & 0.33 & -3.05 \\
\hline 7 & Wushi & 79.20 & 41.20 & 0.02 & 0.07 & 0.03 & 0.11 & 0.05 & -3.31 & 0.25 & -3.33 \\
\hline 8 & Dingxin & 100.20 & 40.98 & 0.09 & 0.03 & 0.06 & 0.19 & 0.05 & -2.06 & 0.23 & -2.15 \\
\hline 9 & Shsanling & 116.22 & 40.25 & 0.15 & 0.08 & 0.14 & 0.21 & 0.04 & 0.08 & 0.27 & -0.07 \\
\hline 10 & Tashikuergan & 75.23 & 37.77 & 0.03 & 0.00 & 0.00 & 0.08 & 0.03 & -0.30 & 0.53 & -0.33 \\
\hline 11 & Yanchi & 107.43 & 37.77 & 0.15 & 0.04 & 0.10 & 0.22 & 0.04 & -0.40 & 0.20 & -0.55 \\
\hline 12 & Delingha & 97.37 & 37.37 & 0.07 & 0.02 & 0.06 & 0.14 & 0.04 & 1.37 & 0.20 & 1.30 \\
\hline 13 & Xining & 101.77 & 36.60 & 0.11 & 0.03 & 0.08 & 0.17 & 0.04 & 1.74 & 0.23 & 1.63 \\
\hline 14 & Taian & 117.15 & 36.25 & 0.15 & 0.07 & 0.15 & 0.18 & 0.04 & 0.43 & 0.36 & 0.28 \\
\hline 15 & Usuda & 138.36 & 36.13 & 0.05 & -0.13 & -0.08 & 0.02 & 0.03 & -0.11 & 0.42 & -0.16 \\
\hline 16 & Xian & 108.98 & 34.17 & 0.15 & 0.06 & 0.13 & 0.19 & 0.04 & -3.43 & 0.25 & -3.58 \\
\hline 17 & Shao & 121.20 & 31.02 & -0.12 & -0.16 & -0.10 & -0.15 & 0.04 & -1.98 & 0.11 & -1.86 \\
\hline 18 & Jiufeng & 114.48 & 30.52 & 0.20 & 0.13 & 0.24 & 0.21 & 0.06 & -2.68 & 0.28 & -2.88 \\
\hline 19 & Lhasa & 91.10 & 29.65 & 0.15 & 0.04 & 0.10 & 0.19 & 0.04 & -2.52 & 0.10 & -2.67 \\
\hline 20 & Luzhou & 100.62 & 28.87 & 0.16 & 0.05 & 0.11 & 0.19 & 0.04 & -1.07 & 0.34 & -1.23 \\
\hline 21 & Kunming & 102.87 & 25.02 & 0.13 & 0.07 & 0.15 & 0.13 & 0.04 & -4.05 & 0.37 & -4.18 \\
\hline 22 & Xiamen & 118.08 & 24.45 & -0.01 & -0.14 & -0.06 & -0.04 & 0.04 & -1.48 & 0.33 & -1.47 \\
\hline 23 & Guangzhou & 113.30 & 23.17 & 0.14 & -0.02 & 0.07 & 0.14 & 0.04 & -3.63 & 0.52 & -3.77 \\
\hline 24 & Qiongzhong & 109.82 & 19.02 & -0.11 & -0.18 & -0.15 & -0.13 & 0.02 & -0.50 & 0.46 & -0.39 \\
\hline
\end{tabular}

Long./Latt.-longitude/latitude; $U^{\mathrm{GIA}} / \sigma_{U} \mathrm{GIA}$ - uplift rate/uncertainty from RF3L20 $(\beta=0.4)+\mathrm{ICE}-4 \mathrm{G}$ model; $U^{\mathrm{GPS}} / \sigma_{U} \mathrm{GPS}-\mathrm{uplift}$ rate/uncertainty from GPS measurement. $U_{3}^{\mathrm{GIA}}, U_{2}^{\mathrm{GIA}}, U_{5}^{\mathrm{GIA}}$ - uplift rates from models RF3+ICE-4G, RF2+ICE-4G and RF3L20( $\left.\beta=0.4\right)+\mathrm{ICE}-5 \mathrm{G}$ respectively; $U^{\prime}$ - uplift rate from GPS measurement with the GIA effect removed.

Table 2. Absolute rotation poles and velocities for Eurasia Plate derived from GIA predictions for the four models in this study and GPS measurements with ITRF 2000 (Altamimi et al., 2002).

\begin{tabular}{|c|c|c|c|c|c|c|c|}
\hline Parameters & $\begin{array}{c}\text { RF3L20 } \\
(\beta=0.4)+\mathrm{ICE}-4 \mathrm{G}\end{array}$ & $\begin{array}{c}\text { RF3 } \\
+\mathrm{ICE} 4 \mathrm{G} \\
\end{array}$ & $\begin{array}{c}\text { RF2 } \\
+\mathrm{ICE} 4 \mathrm{G} \\
\end{array}$ & $\begin{array}{c}\text { RF3L20 } \\
(\beta=0.4)+\mathrm{ICE} 5 \mathrm{G}\end{array}$ & $\sigma^{\mathrm{GIA}}$ & GPS & $\sigma^{\mathrm{GPS}}$ \\
\hline Long. $/{ }^{\circ} \mathrm{E}$ & -26.60 & -31.55 & -33.69 & -30.39 & 2.180 & -99.374 & 2.710 \\
\hline Latt. $/{ }^{\circ} \mathrm{N}$ & -11.26 & -18.45 & -22.26 & -16.97 & 3.430 & 57.965 & 1.211 \\
\hline$\Omega^{\circ} / \mathrm{Ma}$ & 0.0127 & 0.0074 & 0.0102 & 0.0155 & 0.002 & 0.260 & 0.005 \\
\hline
\end{tabular}

Long./Latt._longitude/latitude for the rotation pole; $\Omega$-rotation velocity; $\sigma$ GIA_uncertainty from RF3L20 $(\beta=0.4)+\mathrm{ICE}-4 \mathrm{G}$ model; $\sigma$ GPS uncertainty from GPS measurement.

\subsection{Uncertainties}

Figure 5 shows the predictions for RF2 and the effect of radial pro le with a large viscosity increase in the lower mantle. Similarly, Fig. 6 shows the predictions of RF3L20 $(\beta=0.4)$ with ICE-5G and the effects of very thick ice in Laurentia. The square root of these two differences can be used as a measure of uncertainties for the predictions of GIA model RF3L20 $(\beta=0.4)+\mathrm{ICE}-4 \mathrm{G}$.

With higher viscosity in the lower mantle (RF2), the uplift rates increase by $\sim 0.39 \mathrm{~mm} / \mathrm{yr}$ in the north and reduce by $\sim 0.18 \mathrm{~mm} / \mathrm{yr}$ in the south (Fig. $5(\mathrm{a}, \mathrm{b})$ ). The magnitude of tangential motion increases by $\sim 0.34 \mathrm{~mm} / \mathrm{yr}$ mostly in the south (Fig. 5(c, d)), while the geoid rates increase by $\sim 0.051 \mathrm{~mm} / \mathrm{yr}$ in the north and reduce by $\sim 0.015 \mathrm{~mm} / \mathrm{yr}$ in the south (Fig. 5(e, f)).

When the ICE-5G deglacial model is used, the uplift rate decreased by $\sim 0.33 \mathrm{~mm} / \mathrm{yr}$ in the north and increased by $\sim 0.12 \mathrm{~mm} / \mathrm{yr}$ on the ocean (Fig. $6(\mathrm{a}, \mathrm{b})$ ). On the other hand, the magnitude of the tangential rate increases by $\sim 0.63 \mathrm{~mm} / \mathrm{yr}$ in most parts of East Asia (Fig. 6(c, d)), while the geoidal rate reduces by $\sim 0.028 \mathrm{~mm} / \mathrm{yr}$ in the north and increases by $\sim 0.031 \mathrm{~mm} / \mathrm{yr}$ in the eastern part of the ocean (Fig. 6(e, f)).

The uncertainty of the predictions from GIA model RF3L20 $(\beta=0.4)+\mathrm{ICE}-4 \mathrm{G}$ is calculated using the results of Fig. 5(b, d, f) and Fig. 6(b, d, f), and is shown in Fig. 7. Comparing with the GIA predictions in Fig. 3, these uncertainties are generally small except for the uplift rates in the north of the continent with magnitudes of $\sim 0.23 \mathrm{~mm} / \mathrm{yr}$.

\section{Removing GIA Effects from Crustal Motion and Sea Levels}

The results of GIA predictions from Section 3 can be used to correct high-precision geodetic data in order to reveal uncontaminated signals from other processes of interest, such as tectonic deformation or climate change. In this 

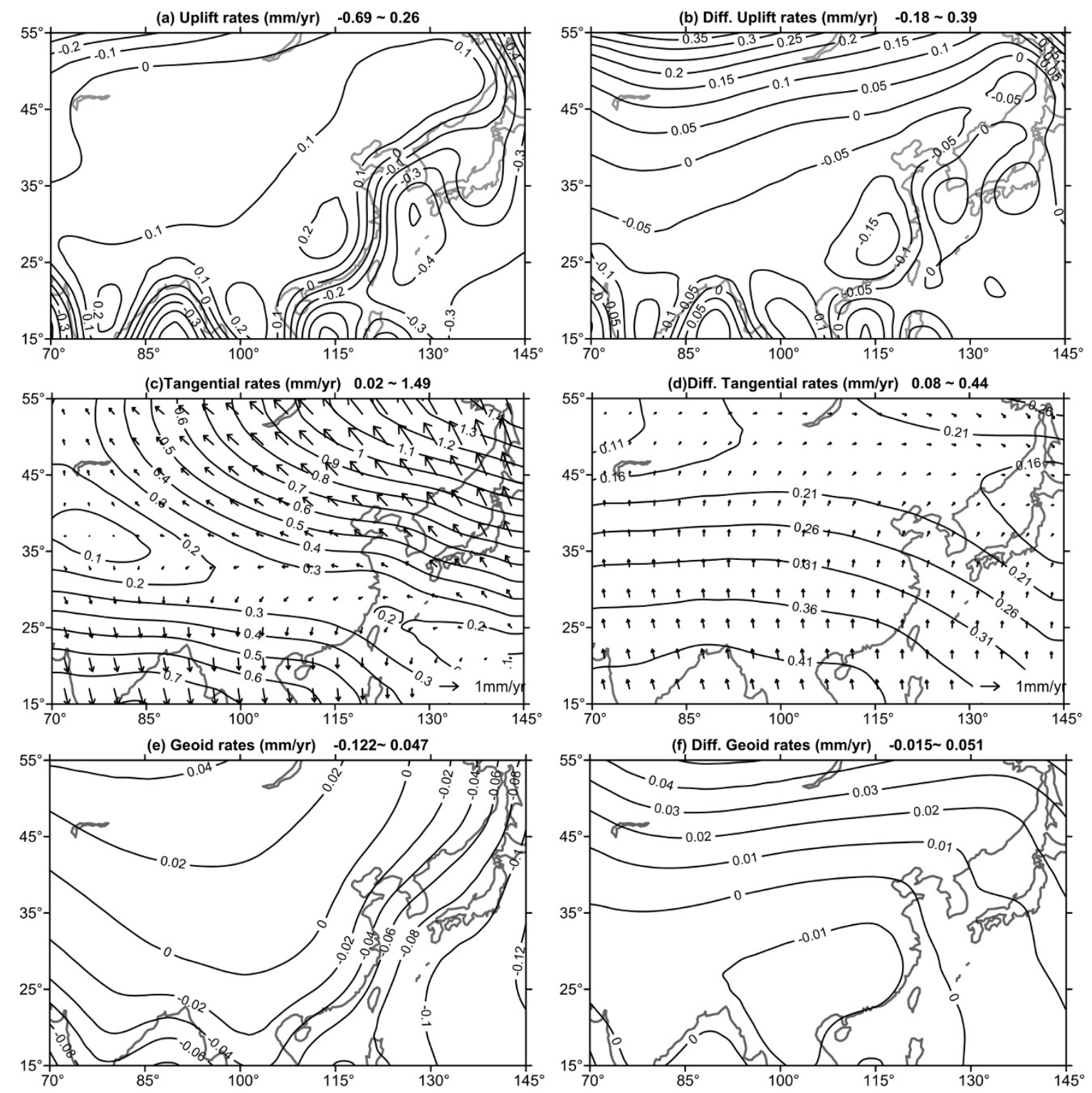

Fig. 5. Effects of higher background viscosity in the lower mantle. Left panels show present-day uplift rates (a), tangential rates (c), and geoid rates (e) in East Asia predicted by the model RF2+ICE-4G. Right panels show their difference when compared with the model RF3+ICE-4G (Fig. 4(a, c, e)). Units are in $\mathrm{mm} / \mathrm{yr}$.

section, the contributions of GIA to the observed crustal motion and sea levels are shown and discussed.

\subsection{Uplift motion}

In Table 1, we have collected secular uplift rates and the uncertainties observed at 24 continuously-recording GPS stations of East Asia (Liu, 2004), in which 22 are from the Crustal Movement Observation Network of China (CMONOC). They are shown in the third and second column from the right. Note that the $\sigma_{U^{\mathrm{GPS}}}$ are deduced from the GPS time series and are not the true uncertainties in uplift rate, which should depend on the time span and density of the GPS stations (e.g., Calais et al., 2006). For a time span of 5 years, the GPS observational error is generally about $2.0 \mathrm{~mm} / \mathrm{yr}$ for the uplift rate and $0.6 \mathrm{~mm} / \mathrm{yr}$ for the tangential velocity. For a time span greater than 8 years, the GPS observational error is generally about $0.5 \mathrm{~mm} / \mathrm{yr}$ for the uplift rate and $0.2 \mathrm{~mm} / \mathrm{yr}$ for the tangential velocity (Wu et al., 2010). GIA predictions and uncertainties from $\operatorname{RF} 3 \mathrm{~L} 20(\beta=0.4)+\mathrm{ICE}-4 \mathrm{G}$ are given in the fth column from the left and the fourth column from the right by using interpolation of Fig. 3(a) and Fig. 7(a). Similarly, using Fig. 4(a), Fig. 5(a) and Fig. 6(a), the predictions from models RF3+ICE-4G, RF2+ICE-4G and $\operatorname{RF} 3 \mathrm{~L} 20(\beta=0.4)+\mathrm{ICE}-5 \mathrm{G}$ are given in the sixth to eighth columns from the left. For most stations, GIA-induced uplift rates are larger than $0.1 \mathrm{~mm} / \mathrm{yr}$ and the uncertainties are generally less than $0.04 \mathrm{~mm} / \mathrm{yr}$.

GIA uplift rates with magnitudes of over $0.15 \mathrm{~mm} / \mathrm{yr}$ are at Suiyang, Changchun, Jixian, Fangshan, Jiufeng, Luzhou. The largest uplift rate is $0.20 \mathrm{~mm} / \mathrm{yr}$ at Jiufeng, Wuhan City, China. GIA uplift rates are nearly zero at Irkutsk, Selezaschita, Wushi, Tashikuergan and Xiamen. Compared with the results from GPS observations, GIA uplift rates are relatively small and are certainly smaller than the current uncertainties in the GPS data. Observed uplift rates with GIA effects removed are shown in the last column. 

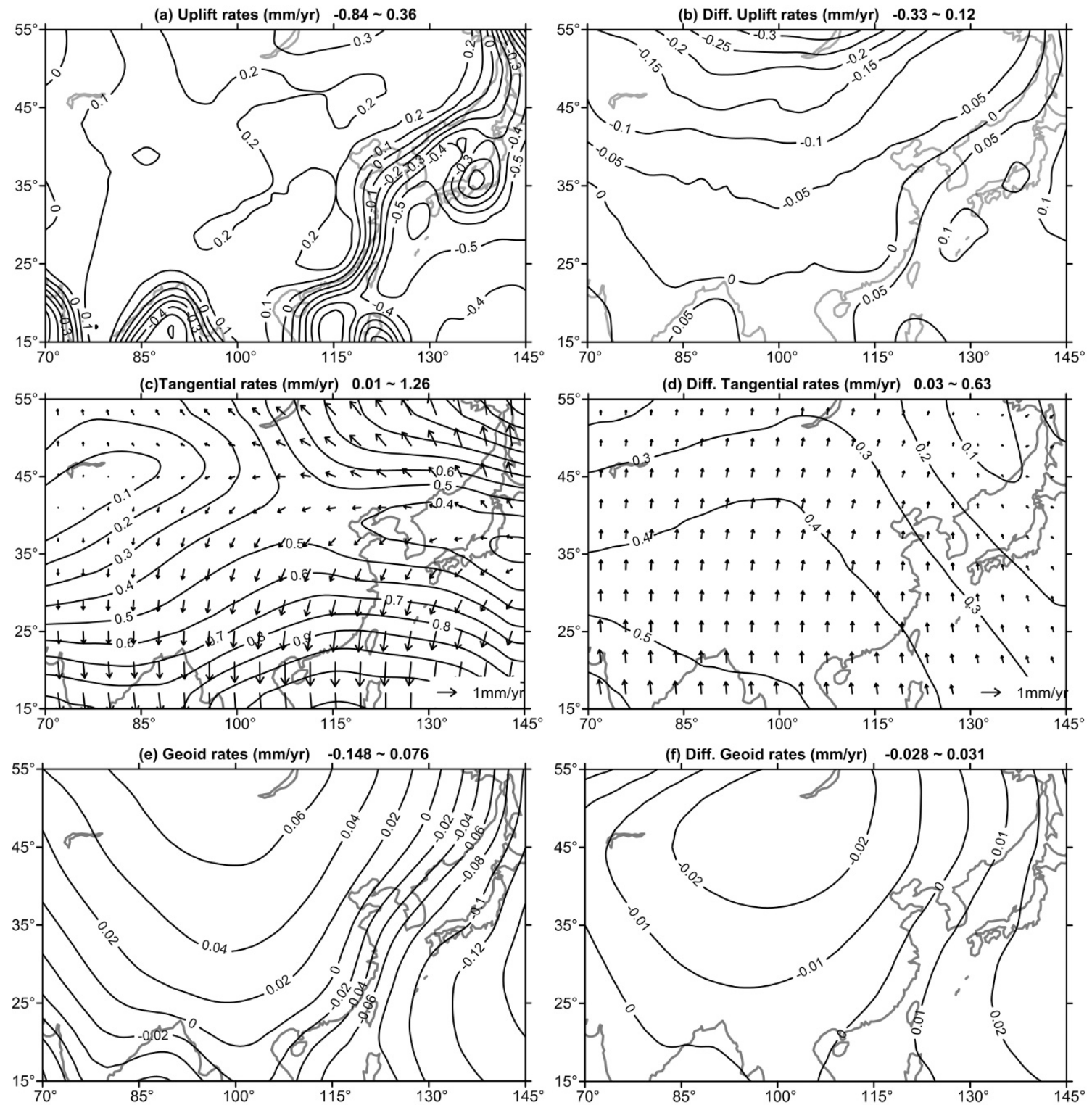

Fig. 6. Effects of ice model. Left panels show present-day uplift rates (a), tangential rates (c), and geoid rates (e) in East Asia predicted by model RF3L20 $(\beta=0.4)+$ ICE-5G. Right panels show their difference when compared with model RF3L20( $\beta=0.4)+$ ICE-4G (Fig. 3(a, b, c)). Units are in $\mathrm{mm} / \mathrm{yr}$.

Present-day height rates are basically crustal motion with respect to geoid. As shown in Fig. 3 and Fig. 7, two leveling sections $\mathrm{AA}^{\prime}, \mathrm{BB}^{\prime}$ with longitudes of $90^{\circ} \mathrm{E}$, $115^{\circ} \mathrm{E}$ are selected going across the Tibetan Plateau and going through the center of the uplift peak at Jian City, China. Figure 8 shows the observed results before (Zhang et al., 1989) and after the GIA corrections based on the RF3L20 $\beta=0.4)+\mathrm{ICE}-4 \mathrm{G}$ model. It is clear that GIA effects are negligible along $\mathrm{AA}^{\prime}$, but along $\mathrm{BB}^{\prime}$ the GIA induced uplift rate is $\sim 0.3 \mathrm{~mm} / \mathrm{yr}$ and is larger than the uncertainties in GIA predictions. However, the corrected height rates are still within the height uncertainties. Thus, if future technology improves height measurement accuracies to about $0.1 \mathrm{~mm} / \mathrm{yr}$ or less, then such correction becomes more meaningful.

\subsection{Tangential motion}

In this paper, the component of the tangential motion due to rotation of the Eurasia Plate has been removed from the GIA predictions and GPS observations (Wang et al., 2001). For the GIA predictions, the rotational parameters are computed for the tangential rates from model RF3L20 $(\beta=0.4)+$ ICE-4G through a least-squares- $\mathrm{t}$ approach using equations (A3) and (A4) of Klemann et al. (2008). As shown in Table 2, the rotational pole is at $\left(26.6^{\circ} \mathrm{W}, 11.26^{\circ} \mathrm{S}\right)$ and the velocity is $0.0127^{\circ} / \mathrm{Ma}$. In the table, the results for GIA models RF3+ICE-4G, RF2+ICE$4 \mathrm{G}, \mathrm{RF} 3 \mathrm{~L} 20(\beta=0.4)+\mathrm{ICE}-5 \mathrm{G}$ are similarly calculated and the uncertainties estimated. Again, the rotational parameters are far larger than their uncertainties. Based on the estimated parameters, the GIA-induced rotational components are computed and shown in Fig. 9(a). Comparing Fig. 9(a) and Fig. 3(b) shows that the rotational components are dominant in the GIA-induced tangential motion of East Asia.

After the rotational components of Fig. 9(a) are removed from Fig. 3(b), the GIA tangential motion relative to Eurasia can be compared with those from GPS measurements 

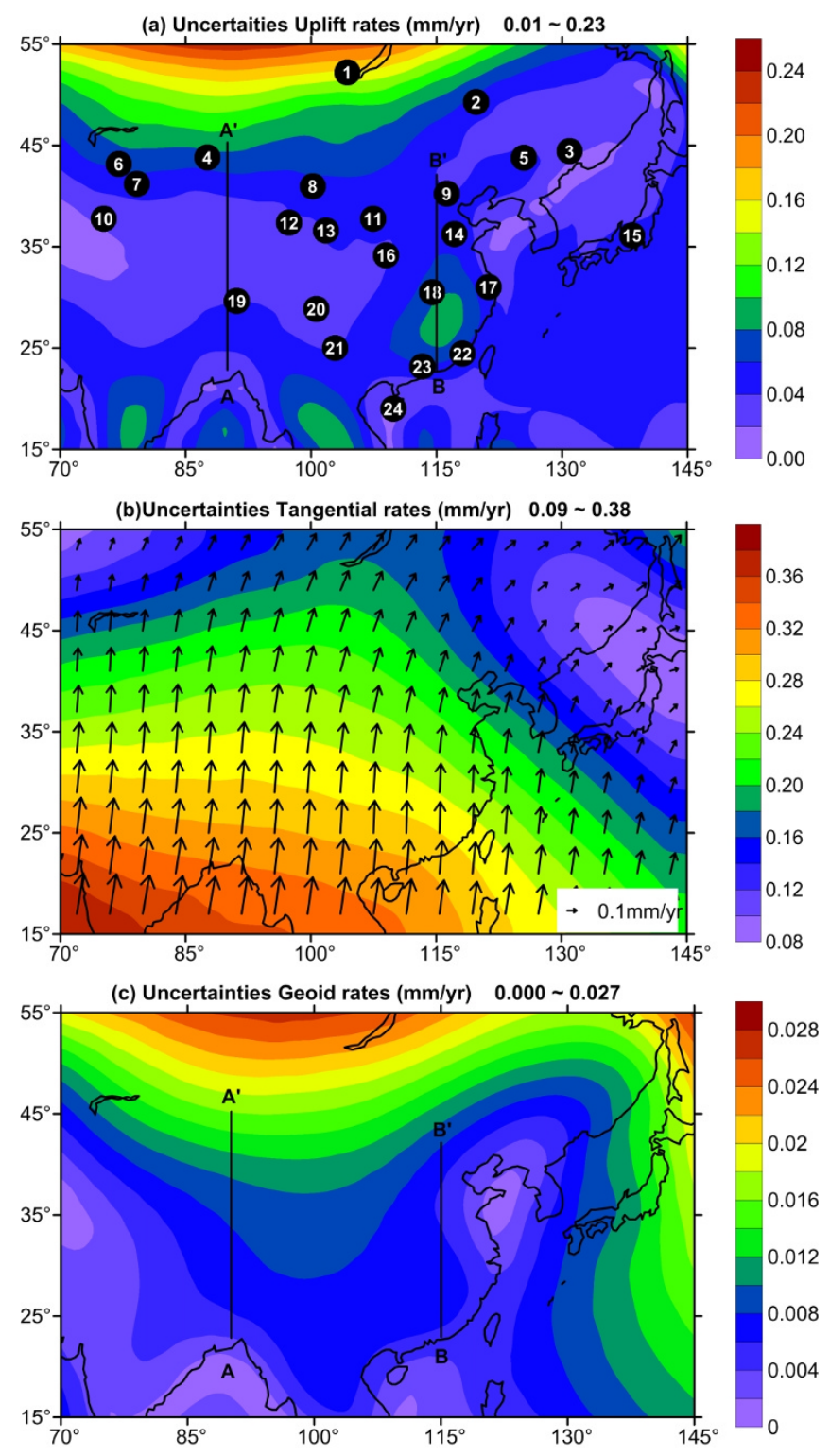

Fig. 7. Uncertainties in the present-day GIA observables (in Fig. 3) predicted by model RF3L20( $\beta=0.4)+$ ICE-4G. (a) uplift-rate uncertainties; (b) tangential-rate uncertainties; (c) geoid-rate uncertainties. The units for the scale bars on the right are in $\mathrm{mm} / \mathrm{yr}$. Black circles with numbers denote the geodetic stations listed in Table 1 .

(Fig. 9(b)). Note that the rotational parameters for the Eurasia Plate tangential motion are from GPS measurements with ITRF 2000 (Altamimi et al., 2002). Figure 9(b) shows that the observed tangential rates are much larger than GIA contributions, especially in the Tibetan Plateau area. Larger GIA contributions are found in two regions, $\mathrm{A}$ and $\mathrm{B}$, in the northeast and southeast of the East Asia. In these two regions, the observed tangential motions have magnitudes less than $\sim 2 \mathrm{~mm} / \mathrm{yr}$, while the GIA contributions can be as much as $1.2 \mathrm{~mm} / \mathrm{yr}$.

\subsection{Sea level change}

In this section, we consider the effects of GIA on both absolute and relative sea-level rates-of-change.

4.3.1 Definition While the absolute sea level (ASL) is measured with respect to the centre of the Earth, the relative sea level (RSL) is measured with respect to the deforming solid Earth surface with uplift rate $\dot{U}$ (Wang et al., 2010). The current rates of changes of ASL and RSL at a given location $(\theta, \phi)$ are given by:

$$
\begin{aligned}
\operatorname{A} \dot{S} L(\theta, \phi)= & {\left[\frac{\dot{\phi}_{1}(\theta, \phi)}{g_{0}}-\frac{1}{A_{\mathrm{O}}}\left\langle\frac{\dot{\phi}_{1}(\theta, \phi)}{g_{0}}-\dot{U}(\theta, \phi)\right\rangle_{\mathrm{O}}\right] } \\
& \cdot O(\theta, \phi)
\end{aligned}
$$

and

$$
\begin{aligned}
& \operatorname{RS} L(\theta, \phi)=\left[\frac{\dot{\phi}_{1}(\theta, \phi)}{g_{0}}-\frac{1}{A_{\mathrm{O}}}\left\langle\frac{\dot{\phi}_{1}(\theta, \phi)}{g_{0}}-\dot{U}(\theta, \phi)\right\rangle_{\mathrm{O}}\right. \\
& -\dot{U}(\theta, \phi)] O(\theta, \phi)
\end{aligned}
$$

Here, the overhead dot denotes a time derivative, $\dot{\phi}_{1} / g_{0}$ is the geoidal rate at the Earth's surface, $O(\theta, \phi)$ is the ocean 
(a) Section AA' (longitude 90 )

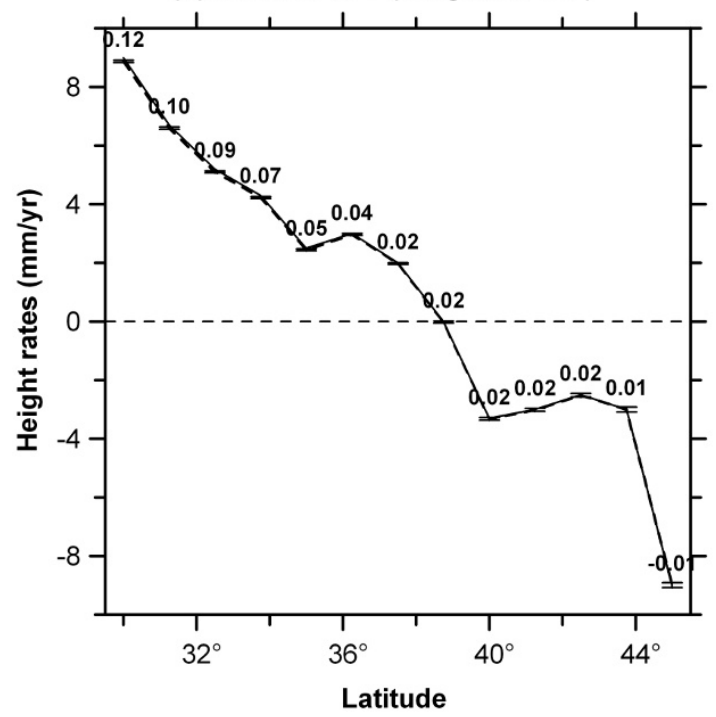

(b) Section BB' (longitude 115)

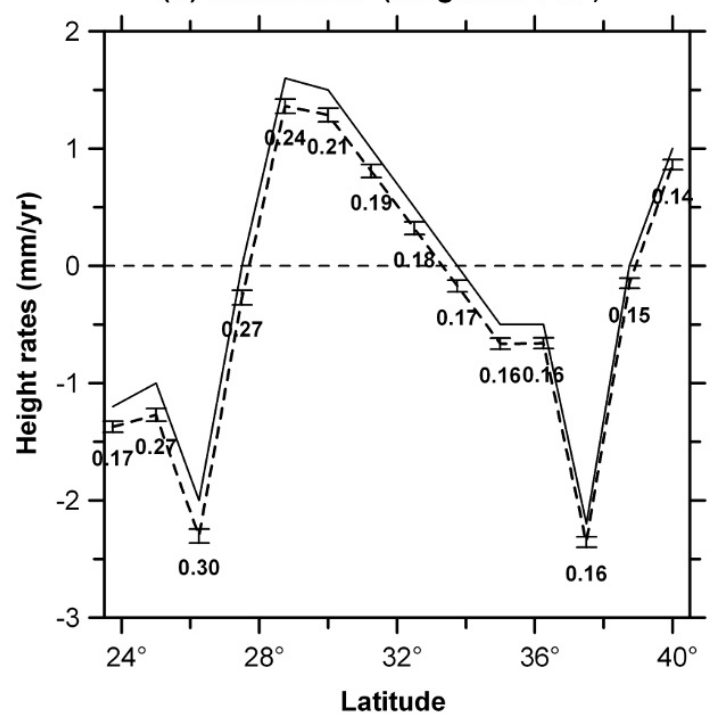

Fig. 8. Present-day height rates from leveling (Zhang et al., 1989) in the two sections of $\mathrm{AA}^{\prime}$ and BB' shown in Fig. 3 and Fig. 7. The solid and dashed lines are the results before and after the GIA corrections based on GIA model RF3L20 $(\beta=0.4)+$ ICE- 4 G. The numbers and error bars indicate the GIA effects and their estimated uncertainties.
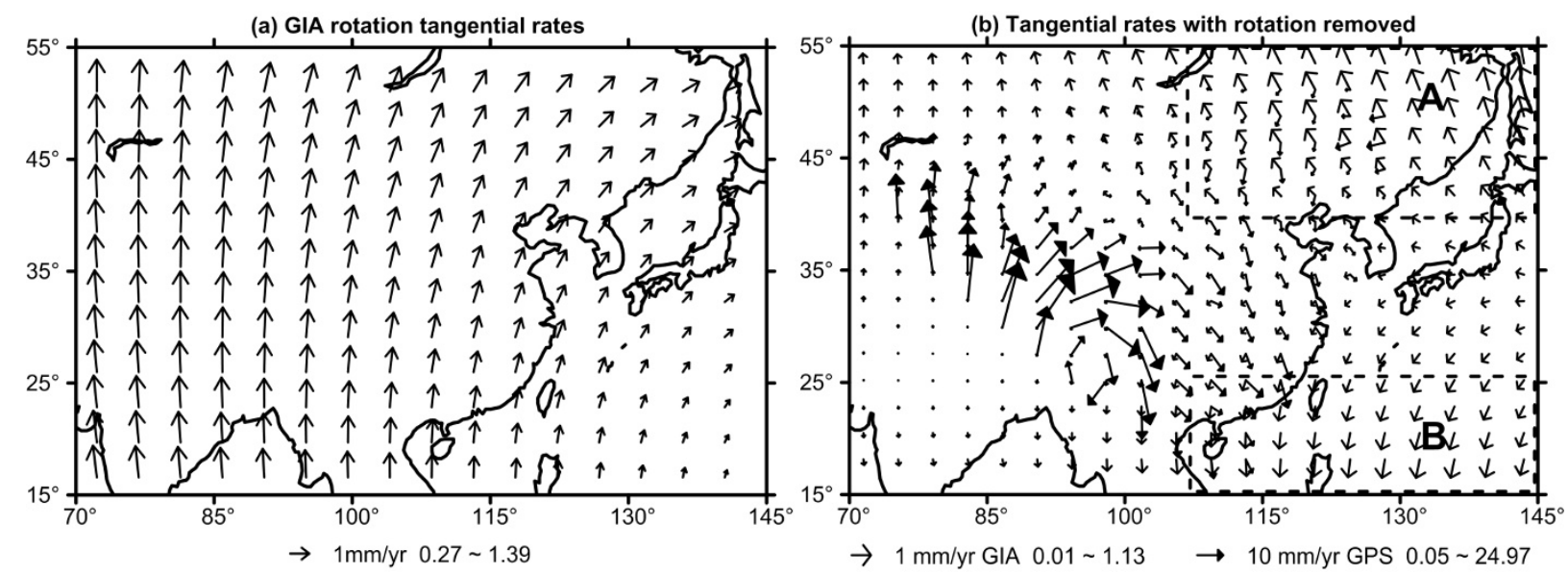

Fig. 9. Present-day tangential rates in East Asia predicted by GIA model RF3L20( $\beta=0.4)+$ ICE-4G and the comparison with GPS measurements (Wang et al., 2001). (a) GIA induced rotation components computed using the rotation parameters in the second column of Table 2; (b) tangential rates with rotation components removed. Vectors with arrow heads not lled are for GIA and the others are for GPS. For the latter ones, rotation components are computed and used with rotation parameters in the seventh column of Table 2 . The length of the arrow is proportional to the magnitude of the tangential velocity. The length scales for the vectors are shown in the bottom of the gures.

function (taking a value of 1 on oceans and a value of 0 on land), $g_{0}$ is the surface gravity, $A_{\mathrm{O}}$ is the area of the global ocean; $\theta$ and $\phi$ are co-latitude and longitude, the subscript $\mathrm{O}$ denotes the global ocean and \langle\rangle$_{\mathrm{O}}$ denotes integration over the global ocean.

Thus, ASL rates, RSL rates and their uncertainties for our models can be computed using Fig. 3 to Fig. 6. The results for model RF3L20 $(\beta=0.4)+\mathrm{ICE}-4 \mathrm{G}$ are shown in Fig. 10 and Fig. 11.

4.3.2 Effect of GIA on ASL rates Figure 10(a), shows that GIA-induced ASL rates in the East Asia Sea increases in magnitude from $0.27 \mathrm{~mm} / \mathrm{yr}$ near the coast to $0.37 \mathrm{~mm} / \mathrm{yr}$ farther to the east, with uncertainties ranging from 0.014 offshore China to $0.042 \mathrm{~mm} / \mathrm{yr}$ to the east and north of Japan. The estimated ASL rates are about 10 times larger than their uncertain- ties. Here, we present the results for GIA-induced ASL rates of several speci c areas: Beibu Gulf, Yellow Sea and Bohai Gulf $0.27 \pm 0.014 \mathrm{~mm} / \mathrm{yr}$; southern coast of China, $0.29 \pm 0.017 \mathrm{~mm} / \mathrm{yr}$; Taiwan Strait and the eastern coast of China $0.30 \pm 0.020 \mathrm{~mm} / \mathrm{yr}$; East China Sea $0.32 \pm 0.022 \mathrm{~mm} / \mathrm{yr}$; Paci c Ocean $0.37 \pm 0.032 \mathrm{~mm} / \mathrm{yr}$.

From satellite altimetry (Topex/Poseidon, Jason 1, ERS and Envisat) data, Zhan et al. (2009) found that the observed secular trends of ASL during the period 1993 2007 in the Yellow Sea and the East China Sea are $3.91 \mathrm{~mm} / \mathrm{yr}$ and $4.28 \mathrm{~mm} / \mathrm{yr}$, respectively. From Fig. 10(a), we see that GIA contributes $0.26 \mathrm{~mm} / \mathrm{yr}$ and $-0.32 \mathrm{~mm} / \mathrm{yr}$ or $6.9 \%$ and $7.5 \%$ of the observed values there. After the GIA corrections, the residual ASL rates are $4.18 \mathrm{~mm} / \mathrm{yr}$, and $4.60 \mathrm{~mm} / \mathrm{yr}$. 
(a) ASL rates $(\mathrm{mm} / \mathrm{yr})$

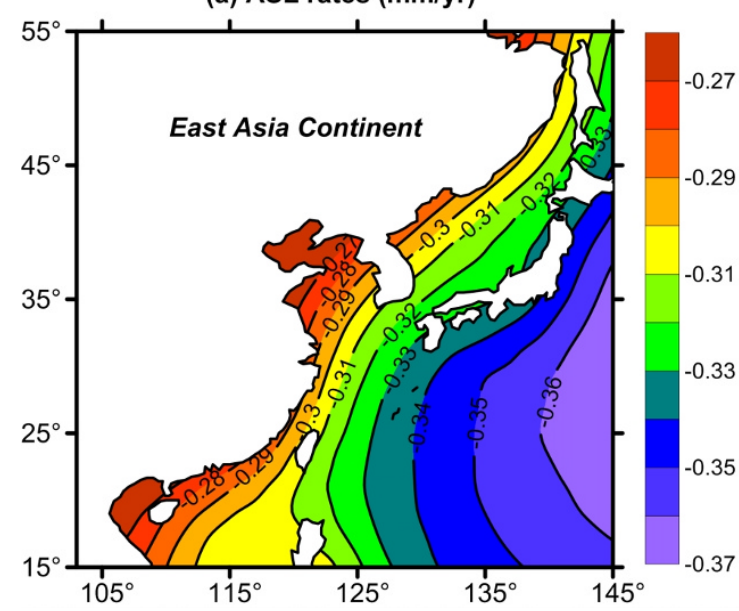

(b) Uncert. of ASL rates (mm/yr)

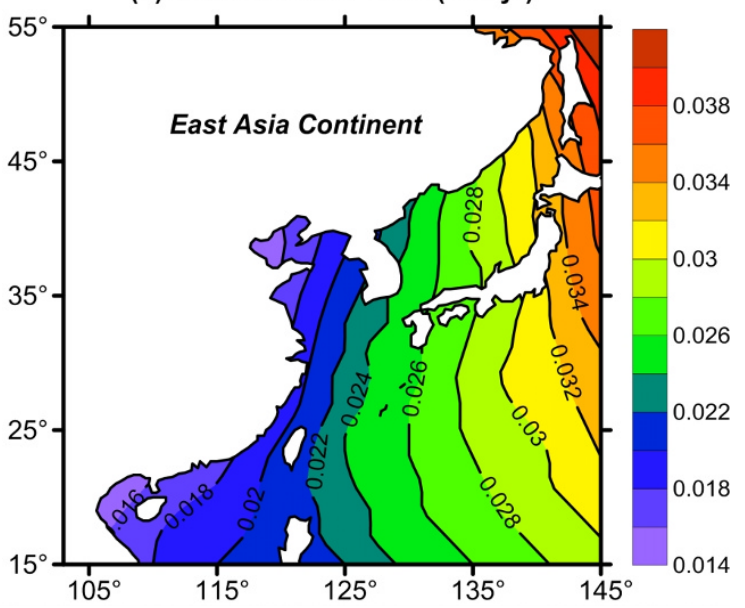

Fig. 10. Present-day ASL rates (a) and the uncertainties (b) for the East Asia Sea predicted from GIA model RF3L20( $\beta=0.4)+\mathrm{ICE}-4 \mathrm{G}$. The units are in $\mathrm{mm} / \mathrm{yr}$.

(a) RSL rates $(\mathrm{mm} / \mathrm{yr})$

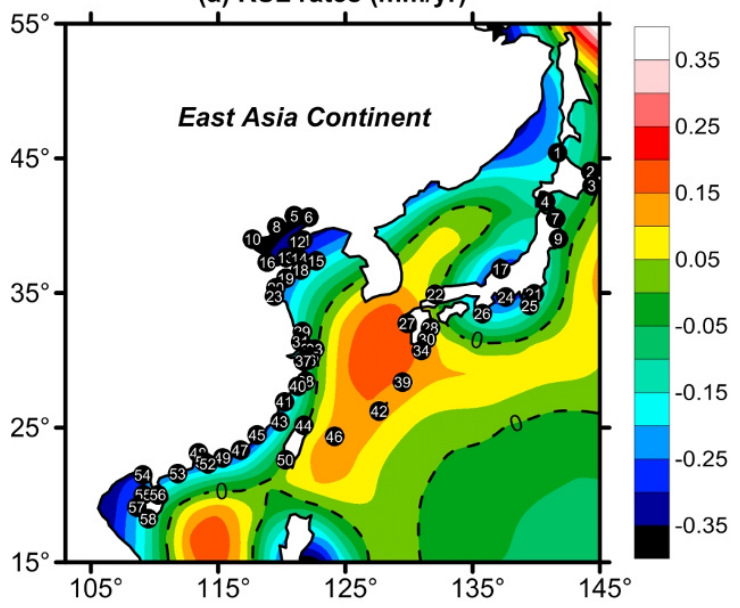

(b) Uncert. of RSL rates (mm/yr)

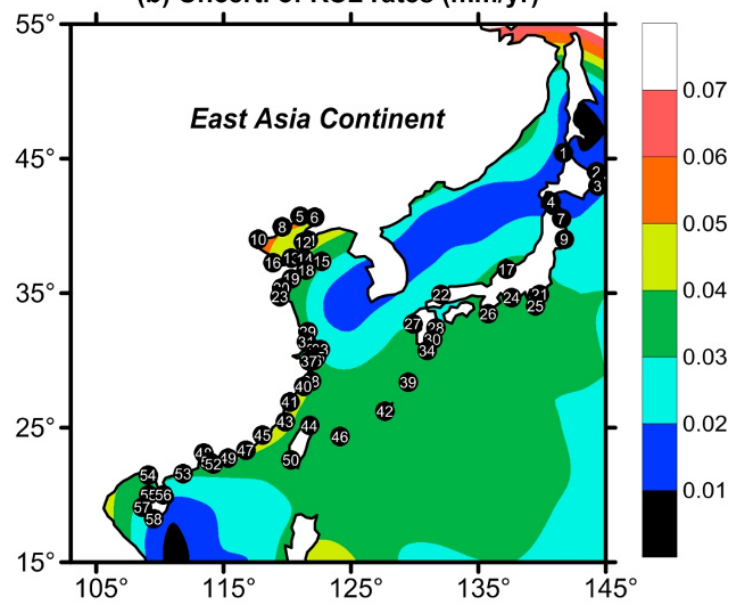

Fig. 11. Present-day RSL rates (a) and the uncertainties (b) for the East Asia Sea from GIA model RF3L20( $\beta=0.4)+\mathrm{ICE}-4 \mathrm{G}$. The units are in mm/yr. The tide gauges are posted in Table 3 .

4.3.3 Effect of GIA on RSL rates Figure 11(a) shows that RSL rates peak around the north of the South China Sea and the East China Sea with magnitudes of $0.20 \pm 0.03 \mathrm{~mm} / \mathrm{yr}$. In the Beibu Gulf and the Bohai Gulf, the GIA-induced RSL rate is $-0.35 \pm 0.05 \mathrm{~mm} / \mathrm{yr}$. To the north, in the Sea of Okhotsk, RSLs are increasing at a rate of $0.25 \pm 0.03 \mathrm{~mm} / \mathrm{yr}$.

Table 3 lists and compares the observed RSL rates in East Asia with GIA-induced RSL rates and their uncertainties. The observed rates are from three decades of tide-gauge data at 58 tide-gauge stations in East Asia (Ding, 2005). On average, the GIA-induced RSL rate is $-0.17 \pm 0.04 \mathrm{~mm} / \mathrm{yr}$ while the observed secular RSL rate is $2.05 \mathrm{~mm} / \mathrm{yr}$, so the RSL rate after GIA correction should be $2.22 \mathrm{~mm} / \mathrm{yr}$. Looking at individual stations in Table 3, we see that there are 14 sites where GIA-induced RSL rates are $-0.3 \sim$ $-0.4 \mathrm{~mm} / \mathrm{yr}$. These are Huludao, Yingkou, Qinghuangdao, Tanggu, Dalian, Lushun, Longkou, Yangjiaogou, Toyama, Shijiusuo, Lianyungang, Maisaka, Shantou and Beihai. For some sites, GIA-induced effects are almost comparable to the observed trend from tide-gauge data. For example, in
Huludao, Yingkou, Dalian, Longkou, and Shijiusuo. On the other hand, the contribution from GIA is nearly zero in Hamada, Luhuashan and Jiong. After GIA corrections, the secular rate of RSL for the 58 tide-gauge data are given in Table 3.

\section{Conclusions}

The effects of GIA on present-day crustal motion and sea-level rates in East Asia have been investigated. The conclusions are as follows.

(1) The effects of lateral variations in lithospheric thickness and mantle viscosity are significant in East Asia and thus should be included in this type of study.

(2) Uncertainties of the GIA predictions due to uncertainties in the radial viscosity profile and in the ice model are small compared with the predicted signals.

(3) For crustal uplift motion on land, the GIA-induced uplift rate peak along the east coast of China has magnitudes of $\sim 0.28 \mathrm{~mm} / \mathrm{yr}$ and uncertainties of $\sim 0.08 \mathrm{~mm} / \mathrm{yr}$. At the 24 GPS stations, the GIA- 
Table 3. Comparisons between the present-day RSL rates at the Tide-Gauge stations of East Asia predicted from GIA model RF3L20( $\beta=0.4)+\mathrm{ICE}-4 \mathrm{G}$ and those from tide gauges (Ding, 2005; Wang et al., 2010).

\begin{tabular}{|c|c|c|c|c|c|c|c|c|c|c|}
\hline Sites & No. & $\begin{array}{l}\text { Long. } \\
{ }^{\circ} \mathrm{E}\end{array}$ & $\begin{array}{c}\text { Latt. } \\
{ }^{\circ} \mathrm{N}\end{array}$ & $\begin{array}{c}s^{\mathrm{GIA}} \\
\mathrm{mm} / \mathrm{yr}\end{array}$ & $\begin{array}{c}s_{3}^{\mathrm{GIA}} \\
\mathrm{mm} / \mathrm{yr}\end{array}$ & $\begin{array}{c}s_{2}^{\mathrm{GIA}} \\
\mathrm{mm} / \mathrm{yr}\end{array}$ & $\begin{array}{c}s_{5}^{\mathrm{GIA}} \\
\mathrm{mm} / \mathrm{yr}\end{array}$ & $\begin{array}{c}\sigma_{S}^{\mathrm{GIA}} \\
\mathrm{mm} / \mathrm{yr}\end{array}$ & $\begin{array}{c}s^{\mathrm{TG}} \\
\mathrm{mm} / \mathrm{yr}\end{array}$ & $\begin{array}{c}s^{\prime} \\
\mathrm{mm} / \mathrm{yr}\end{array}$ \\
\hline Wakkanai & 1 & 141.68 & 45.42 & -0.18 & -0.21 & -0.24 & -0.18 & 0.02 & 2.9 & 3.08 \\
\hline Abashiri & 2 & 144.28 & 44.02 & -0.07 & -0.09 & -0.10 & -0.04 & 0.01 & 1.63 & 1.7 \\
\hline Kushiro & 3 & 144.38 & 42.97 & -0.02 & -0.06 & -0.07 & 0.01 & 0.02 & 8.97 & 8.99 \\
\hline Hakodate & 4 & 140.73 & 41.78 & -0.11 & -0.15 & -0.18 & -0.10 & 0.02 & -0.14 & -0.03 \\
\hline Huludao & 5 & 121.00 & 40.72 & -0.39 & -0.32 & -0.40 & -0.46 & 0.05 & 0.68 & 1.07 \\
\hline Yingkou & 6 & 122.15 & 40.63 & -0.37 & -0.32 & -0.40 & -0.44 & 0.05 & 1.8 & 2.17 \\
\hline Hachinohe & 7 & 141.53 & 40.53 & -0.11 & -0.13 & -0.16 & -0.09 & 0.02 & 5.14 & 5.25 \\
\hline Qinghuangdao & 8 & 119.62 & 39.92 & -0.39 & -0.32 & -0.40 & -0.46 & 0.05 & -2.12 & -1.73 \\
\hline Ofunato & 9 & 141.75 & 39.02 & -0.10 & -0.12 & -0.16 & -0.08 & 0.02 & 5.23 & 5.33 \\
\hline Tanggu & 10 & 117.72 & 39.00 & -0.40 & -0.31 & -0.40 & -0.46 & 0.05 & 2.3 & 2.7 \\
\hline Dalian & 11 & 121.67 & 38.92 & -0.32 & -0.28 & -0.35 & -0.37 & 0.05 & 1.51 & 1.83 \\
\hline Lushun & 12 & 121.25 & 38.80 & -0.32 & -0.28 & -0.35 & -0.37 & 0.05 & 5.38 & 5.7 \\
\hline Longkou & 13 & 120.32 & 37.62 & -0.32 & -0.27 & -0.35 & -0.36 & 0.05 & 0.08 & 0.4 \\
\hline Yantai & 14 & 121.38 & 37.55 & -0.27 & -0.24 & -0.31 & -0.31 & 0.04 & 0.12 & 0.39 \\
\hline Chengshantou & 15 & 122.70 & 37.38 & -0.22 & -0.19 & -0.25 & -0.25 & 0.03 & -1.19 & -0.97 \\
\hline Yangjiaogou & 16 & 118.87 & 37.27 & -0.36 & -0.29 & -0.38 & -0.41 & 0.05 & 3.35 & 3.71 \\
\hline Toyama & 17 & 137.22 & 36.77 & -0.33 & -0.16 & -0.23 & -0.34 & 0.04 & 2.3 & 2.63 \\
\hline Yushankou & 18 & 121.48 & 36.70 & -0.23 & -0.20 & -0.26 & -0.26 & 0.04 & -2.18 & -1.95 \\
\hline Qingdao & 19 & 120.32 & 36.08 & -0.27 & -0.24 & -0.32 & -0.31 & 0.04 & 0.64 & 0.91 \\
\hline Shijiusuo & 20 & 119.55 & 35.38 & -0.30 & -0.25 & -0.33 & -0.33 & 0.05 & 0.36 & 0.66 \\
\hline Mera & 21 & 139.83 & 34.92 & -0.20 & -0.14 & -0.21 & -0.19 & 0.04 & 3.46 & 3.66 \\
\hline Hamada & 22 & 132.07 & 34.90 & 0 & 0.01 & -0.03 & 0.03 & 0.03 & 5.88 & 5.88 \\
\hline Lianyungang & 23 & 119.42 & 34.75 & -0.30 & -0.25 & -0.33 & -0.32 & 0.05 & -1.91 & -1.61 \\
\hline Maisaka & 24 & 137.62 & 34.68 & -0.31 & -0.15 & -0.23 & -0.32 & 0.04 & -2.23 & -1.92 \\
\hline Miyakejima & 25 & 139.48 & 34.06 & -0.14 & -0.12 & -0.19 & -0.12 & 0.04 & -3.7 & -3.56 \\
\hline Kushimoto & 26 & 135.78 & 33.47 & -0.26 & -0.11 & -0.19 & -0.26 & 0.04 & 2.24 & 2.5 \\
\hline Nagasaki & 27 & 129.87 & 32.73 & 0.17 & 0.16 & 0.13 & 0.23 & 0.03 & 3.13 & 2.96 \\
\hline Hosojima & 28 & 131.68 & 32.42 & 0.07 & 0.08 & 0.03 & 0.11 & 0.03 & -0.57 & -0.64 \\
\hline Lvsi & 29 & 121.62 & 32.13 & -0.09 & -0.07 & -0.13 & -0.09 & 0.03 & 5.91 & 6 \\
\hline Aburatsu & 30 & 131.42 & 31.57 & 0.09 & 0.10 & 0.05 & 0.13 & 0.03 & 1.13 & 1.04 \\
\hline Wusong & 31 & 121.50 & 31.38 & -0.13 & -0.10 & -0.16 & -0.13 & 0.03 & 2.61 & 2.74 \\
\hline Dajishan & 32 & 122.17 & 30.82 & -0.05 & -0.02 & -0.08 & -0.03 & 0.03 & 4.68 & 4.73 \\
\hline Luhuashan & 33 & 122.60 & 30.82 & -0.03 & 0 & -0.06 & -0.01 & 0.03 & 3.36 & 3.39 \\
\hline Nishinoomote & 34 & 130.99 & 30.73 & 0.13 & 0.13 & 0.08 & 0.18 & 0.04 & 2.19 & 2.06 \\
\hline Changtu & 35 & 122.30 & 30.25 & -0.07 & -0.04 & -0.11 & -0.06 & 0.03 & 2.09 & 2.16 \\
\hline Dinghai & 36 & 122.07 & 30.00 & -0.09 & -0.05 & -0.12 & -0.07 & 0.03 & 3.74 & 3.83 \\
\hline Zhenhai & 37 & 121.72 & 29.95 & -0.09 & -0.06 & -0.13 & -0.08 & 0.03 & 4.18 & 4.27 \\
\hline Dachen & 38 & 121.90 & 28.45 & -0.10 & -0.05 & -0.13 & -0.08 & 0.04 & 2.92 & 3.02 \\
\hline Naze & 39 & 129.50 & 28.38 & 0.13 & 0.16 & 0.11 & 0.19 & 0.04 & 2.44 & 2.31 \\
\hline Kanmen & 40 & 121.28 & 28.08 & -0.14 & -0.08 & -0.16 & -0.13 & 0.04 & 1.59 & 1.73 \\
\hline Sansha & 41 & 120.22 & 26.92 & -0.22 & -0.12 & -0.21 & -0.22 & 0.04 & 0.23 & 0.45 \\
\hline Naha & 42 & 127.67 & 26.22 & 0.12 & 0.15 & 0.10 & 0.17 & 0.04 & 1.79 & 1.67 \\
\hline Pingtan & 43 & 119.85 & 25.45 & -0.24 & -0.13 & -0.22 & -0.24 & 0.04 & 1.02 & 1.26 \\
\hline Jilong & 44 & 121.75 & 25.15 & 0 & 0 & -0.06 & 0.03 & 0.04 & 4.71 & 4.71 \\
\hline Xiamen & 45 & 118.07 & 24.45 & -0.28 & -0.15 & -0.24 & -0.28 & 0.04 & 5.73 & 6.01 \\
\hline Ishigaki & 46 & 124.15 & 24.33 & 0.16 & 0.13 & 0.08 & 0.22 & 0.04 & 1.84 & 1.68 \\
\hline Shantou & 47 & 116.75 & 23.33 & -0.30 & -0.17 & -0.26 & -0.31 & 0.04 & -1.19 & -0.89 \\
\hline Huangpu & 48 & 113.45 & 23.10 & -0.40 & -0.25 & -0.34 & -0.42 & 0.05 & 0.07 & 0.47 \\
\hline Shanwei & 49 & 115.35 & 22.75 & -0.28 & -0.17 & -0.25 & -0.29 & 0.04 & 1.18 & 1.46 \\
\hline Gaoxiong & 50 & 120.29 & 22.61 & 0.07 & 0.03 & -0.02 & 0.11 & 0.03 & 4.49 & 4.42 \\
\hline Chiwan & 51 & 113.87 & 22.47 & -0.27 & -0.18 & -0.26 & -0.28 & 0.04 & 0.25 & 0.52 \\
\hline Hongkong & 52 & 114.20 & 22.30 & -0.24 & -0.17 & -0.24 & -0.25 & 0.04 & 1.24 & 1.48 \\
\hline Zhapo & 53 & 111.83 & 21.58 & -0.29 & -0.20 & -0.27 & -0.30 & 0.04 & 1.69 & 1.98 \\
\hline Beihai & 54 & 109.08 & 21.48 & -0.32 & -0.24 & -0.31 & -0.34 & 0.04 & 1.74 & 2.06 \\
\hline Weizhou & 55 & 109.12 & 20.02 & -0.24 & -0.18 & -0.24 & -0.26 & 0.03 & 3.16 & 3.4 \\
\hline Haikou & 56 & 110.28 & 20.02 & -0.18 & -0.13 & -0.18 & -0.19 & 0.02 & 6.85 & 7.03 \\
\hline Dongfang & 57 & 108.62 & 19.10 & -0.23 & -0.16 & -0.21 & -0.25 & 0.03 & 2.88 & 3.11 \\
\hline Yulin & 58 & 109.53 & 18.22 & -0.12 & -0.05 & -0.08 & -0.13 & 0.02 & 1.39 & 1.51 \\
\hline Average & & & & -0.17 & & & & 0.04 & 2.05 & 2.22 \\
\hline
\end{tabular}

Long./Latt.—longitude/latitude; $s^{\mathrm{GIA}} / \sigma_{S}^{\mathrm{GIA}}$ —RSL rate/uncertainty from RF3L20( $\left.\beta=0.4\right)+\mathrm{ICE}-4 \mathrm{G}$ model; $s^{\mathrm{TG}} / s^{\prime}$ —RSL rate before/after GIA correction. $s_{3}^{\mathrm{GIA}}, s_{2}^{\mathrm{GIA}}, s_{5}^{\mathrm{GIA}}$-RSL rates from models RF3+ICE-4G, RF2+ICE-4G and RF3L20( $\left.\beta=0.4\right)+\mathrm{ICE}-5 \mathrm{G}$, respectively. 
induced uplift rates are generally larger than $0.1 \mathrm{~mm} / \mathrm{yr}$ with uncertainties about $0.04 \mathrm{~mm} / \mathrm{yr}$. The largest uplift rate is $0.20 \mathrm{~mm} / \mathrm{yr}$ at Jiufeng, Wuhan City, China. For the leveling pro le going through Jian City, China, GIA contributes about $\sim 0.3 \mathrm{~mm} / \mathrm{yr}$. For the tangential motion, with the component due to the rotation of the Eurasian Plate removed, the GIA contribution is $\sim 1.2 \mathrm{~mm} / \mathrm{yr}$ and is small compared to the observed rate in East Asia. The largest GIA-induced tangential motion occurs in the northeast and southeast of East Asia where the GIA contributions are not negligible compared with the GPS observed value.

(4) For the sea levels, the GIA-induced ASL rate ranges from $-0.27 \mathrm{~mm} / \mathrm{yr}$ near the coast to $-0.37 \mathrm{~mm} / \mathrm{yr}$ farther in the ocean to the east, the magnitude of the estimated signals is usually 10 times higher than the uncertainties. In the Yellow Sea and the East China Sea, GIA effects are $6.9 \%$ and $7.5 \%$ of the secular ASL rate observed by satellite altimetry. In the East China Sea, the RSL rates induced by GIA can be $0.20 \pm 0.03 \mathrm{~mm} / \mathrm{yr}$. Comparing these with RSL rates from tide-gauge data in East Asia, the GIA-induced RSL rate is, in general, a factor of ten smaller than the observed secular RSL rate, and the average RSL rate after removing the effect of GIA is $\sim 2.22 \mathrm{~mm} / \mathrm{yr}$.

(5) The contributions from GIA estimated in this paper can be used for the GIA correction of the observation data in East Asia, so that the signals from other processes such as global change or tectonics can be revealed in this area.

Acknowledgments. We thank Dr. Wouter van der Wal and an anonymous reviewer for their very helpful comments and suggestions. The FE calculation was performed with the ABAQUS package from SIMULIA. H. Wang is supported by National Natural Science Fundation of China (Grant No. 40825012, 41021003, 41174016), CAS/SAFEA International Partnership Program for Creative Research Teams, and an Opening Fund of KLDG Laboratory of CAS (L09-02, L09-18). P. Wu is supported by an Operating Grant from NSERC of Canada. L. Jiang is supported by Hundred Talents Program of the Chinese Academy of Sciences, and National Key Technology Research and Development Program of the Ministry of Science and Technology of China (No. 2011BAK12B02).

\section{References}

Altamimi, Z., P. Sillard, and C. Boucher, ITRF2000: A new release of the International Terrestrial Reference Frame for earth science applications, J. Geophys. Res., 107(B10), 2214, doi:10.1029/2001JB000561, 2002.

Calais, E., J. Y. Han, C. DeMets, and J. M. Nocquet, Deformation of the North American plate interior from a decade of continuous GPS measurements, J. Geophys. Res., 111, B06402, doi:10.1029/2005JB004253, 2006.

Davis, J. L. and J. X. Mitrovica, Glacial isostatic adjustment and the anomalous tide gauges record of eastern North America, Nature, 379, 331-332, 1996.

Ding, Y. H., The effect of sea level variation on the calculation of engineering water level, MSc Thesis, Ocean University of China, 2005.

Ekstrom, G. and A. Dziewonski, The unique anisotropy of the Paci c upper mantle, Nature, 394, 168-172, 1998.

Gasperini, P. and R. Sabadini, Lateral heterogeneities in mantle viscosity and postglacial rebound, Geophys. J., 98, 413-428, 1989.

Giunchi, C., G. Spada, and R. Sabadini, Lateral viscosity variations and postglacial rebound: effects on present-day VLBI baseline deformation, Geophys. Res. Lett., 24, 13-16, 1997.
Han, G. and W. Huang, Low-frequency sea-level variability in the South China Sea and its relationship to ENSO, Theor. Appl. Climatol., 97, 4152, 2009.

Ivins, E. R. and C. G. Sammis, On lateral viscosity contrast in the mantle and the rheology of low-frequency geodynamics, Geophys. J. Int., 123, 305-322, 1995.

Kaufmann, G. and K. Lambeck, Mantle dynamics, postglacial rebound and the radial viscosity pro le, Phys. Earth Planet. Inter., 121, 301-324, 2000.

Kaufmann, G. and P. Wu, Lateral asthenospheric viscosity variations and postglacial rebound: a case study for the Barents Sea, Geophys. Res. Lett., 25, 1963-1966, 1998.

Kaufmann, G. and P. Wu, Glacial isostatic adjustment in Fennoscandia with a three dimensional viscosity structure as an inverse problem, Earth Planet. Sci. Lett., 197, 1-10, 2002.

Kaufmann, G., P. Wu, and D. Wolf, Some effects of lateral heterogeneities in the upper mantle on postglacial land uplift close to continental margins, Geophys. J. Int., 128, 175-187, 1997.

Kaufmann, G., P. Wu, and G. Li, Glacial isostatic adjustment in Fennoscandia for a laterally heterogeneous earth, Geophys. J. Int., 143, 262-273, 2000.

Kaufmann, G., P. Wu, and E. R. Ivins, Lateral viscosity variations beneath Antarctica and their implications on regional rebound motions and seismotectonics, J. Geodyn., 39, 165-181, doi:10.1016/j.jog.2004.08.009, 2005.

Klemann, V., Z. Martinec, and E. R. Ivins, Glacial isostasy and plate motion, J. Geodyn., 46(3-5), 95-103, doi:10.1016/j.jog.2008.04.005, 2008.

Kuo, C. Y., C. K. Shum, A. Braun, K. C. Cheng, and Y. Yi, Vertical motion determined using satellite altimetry and tide gauges, Terr. Atmos. Ocean. Sci., 19(1-2), 21-35, 2008.

Latychev, L., J. X. Mitrovica, M. E. Tamisiea, J. Tromp, and R. Moucha, In uence of lithospheric thickness variations on 3-D crustal velocities due to glacial isostatic adjustment, Geophys. Res. Lett., 32, L01304, doi:10.1029/2004GL021454, 2005a.

Latychev, L., J. X. Mitrovica, J. Tromp, M. E. Tamisiea, D. Komatitsch, and C. C. Christara, Glacial isostatic adjustment on 3-D Earth models: a nite volume formulation, Geophys. J. Int., 161, 421-444, doi: 10.1111/j.1365-246X.2005.02536.x, 2005b.

Lidberg, M., J. M. Johansson, H. Scherneck, and J. L. Davis, An improved and extended GPS-derived 3D velocity eld of the glacial isostatic adjustment (GIA) in Fennoscandia, J. Geod., 81, 213-230, doi:10.1007/s00190-006-0102-4, 2007.

Liu, G., Key issues relating to high precision GPS positioning and crustal deformation analysis, Ph.D. Thesis, Graduate University of Chinese Academy of Sciences, 2004.

Mitrovica, J. X. and A. M. Forte, Radial pro le of mantle viscosity: results from a joint inversion of convection and post-glacial rebound observables, J. Geophys. Res., 102(B2), 2751-2769, 1997.

Paulson, A., S. Zhong, and J. Wahr, Modeling post-glacial rebound with lateral viscosity variations, Geophys. J. Int., 163(1), 357-371, doi:10.1111/j.1365-246X. 2005.02645.x, 2005.

Peltier, W. R., Deglaciation-induced vertical motion of the NorthAmerican continent and transient lower mantle rheology, J. Geophys. Res., 91(B9), 9099-9123, 1986.

Peltier, W. R., Ice age paleotopography, Science, 265, 195-201, 1994.

Peltier, W. R., Postglacial variations in the level of the sea: implications for climate dynamics and solid-earth geophysics, Rev. Geophys., 36, 603689, 1998.

Peltier, W. R., Global glacial isostasy and the surface of the ice age earth: the ICE-5G (VM2) Model and GRACE, Ann. Rev. Earth Planet. Sci., 32, 111-149, 2004.

Sabadini, R., D. A. Yuen, and M. Portney, The effects of upper mantle lateral heterogeneities on postglacial rebound, Geophys. Res. Lett., 13(4), 337-340, 1986.

Sella, G. F., S. Stein, T. H. Dixon, M. Craymer, T. S. James, S. Mazzotti, and R. K. Dokka, Observation of glacial isostatic adjustment in "stable" North America with GPS, Geophs. Res. Lett., 34, L02306, doi:10.1029/2006GL027081, 2007.

Trisirisatayawong, I., M. Naeijeb, W. Simonsb, and L. Fenoglio-Marc, Sea level change in the Gulf of Thailand from GPS-corrected tide gauge data and multi-satellite altimetry, Global Planet. Change, 76(3-4), 137-151, 2011.

Tushingham, A. M. and W. R. Peltier, ICE-3G: A new global model of late Pleistocence deglaciation based upon geophysical predictions of postglacial relative sea level change, J. Geophys. Res., 96, 4497-4523, 1991. 
van der Wal, W., P. Wu, M. G. Sideris, and C. K. Shum, Use of GRACE determined secular gravity rates for glacial isostatic adjustment studies in North-America, J. Geodyn., 46(3-5), 144-154, 2008.

Wang, H., Effects of glacial isostatic adjustment since the late Pleistocene on the uplift of the Tibetan Plateau, Geophys. J. Int., 144(2), 448-458, 2001.

Wang, H. and P. Wu, Effects of lateral variations in lithospheric thickness and mantle viscosity on glacially induced surface motion on a spherical, self-gravitating Maxwell Earth, Earth Planet. Sci. Lett., 244, 576-589, 2006 .

Wang, H. and P. Wu, Effects of lateral variations in lithospheric thickness and mantle viscosity on glacially induced relative sea levels and long wavelength gravity eld in a spherical, self-gravitating Maxwell Earth, Earth Planet. Sci. Lett., 249, 368-383, 2006b.

Wang, H., P. Wu, and W. van der Wal, Using postglacial sea level, crustal velocities and gravity-rate-of-change to constrain the in uence of thermal effects on mantle lateral heterogeneities, J. Geodyn., 46(3-5), 104$117,2008$.

Wang, H., P. Wu, W. van der Wal, L. Jia, B. Hu, and Z. Wang, Glacial isostatic adjustment model constrained by geodetic measurements and relative sea level, Chinese J. Geophys., 52(10), 2450-2460, 2009 (in Chinese).

Wang, H., L. Jia, P. Wu, and B. Hu, Effects of global glacial isostatic adjustment on the secular changes of gravity, and sea level in East Asia, Chinese J. Geophys., 53(11), 2590-2602, 2010 (in Chinese).

Wang, Q., P. Z. Zhang, J. T. Freymueller, R. Bilham, K. M. Larson, X. Lai, X. You, Z. Niu, J. Wu, Y. Li, J. Liu, Z. Yang, and Q. Chen, Present-day crustal deformation in China constrained by global positioning system, Measurements, Science, 294, 574-577, 2001.

Wu, P., Using commercial nite element packages for the study of earth deformations, sea levels and the state of stress, Geophys. J. Int., 158 , 401-408, doi:10.1111/j.1365-246X.2004.02338.x, 2004.

$\mathrm{Wu}, \mathrm{P}$. , Effects of lateral variations in lithospheric thickness and mantle viscosity on glacially induced surface motion in Laurentia, Earth Planet. Sci. Lett., 235, 549-563, doi:10.1016/j.epsl.2005.04.038, 2005.

$\mathrm{Wu}, \mathrm{P}$., Sensitivity of relative sea levels and crustal velocities in Laurentide to radial and lateral viscosity variations in the mantle, Geophys. J. Int., 165, 401-413, doi:10.1111/j.1365-246X.2006.02960.x, 2006.

Wu, P., H. Steffen, and H. Wang, Optimal locations for GPS measurements in North America and northern Europe for constraining Glacial Isostatic Adjustment, Geophys. J. Int., 181, 653-664, doi:10.1111/j.1365246X.2010.04545.x, 2010.

Zhan, J. G., Y. Wang, and Y. S. Cheng, The analysis of China sea level change, Chinese J. Geophys., 52(7), 1725-1733, 2009 (in Chinese).

Zhang, Z., S. Geng, D. Chen, S. Ying, Z. Wang, Z. He, S. Xia, and J. Wang, Rate of recent vertical crustal deformation, in Lithospheric Dynamics Atlas of China, edited by Ma, X., G. Ding, W. Gao, H. Zhang, B. Zhang, and Z. Ma, 18pp., China Cartographic Publishing House, Beijing, 1989.

H. Wang (e-mail: whs@asch.whigg.ac.cn), P. Wu, L. Jia, B. Hu, and L. Jiang 